Document downloaded from:

http://hdl.handle.net/10251/171223

This paper must be cited as:

Gisbert-Roca, F.; Garcia-Bernabe, A.; Compañ Moreno, V.; Martínez-Ramos, C.; Monleón Pradas, M. (2021). Solid Polymer Electrolytes Based on Polylactic Acid Nanofiber Mats Coated with Polypyrrole. Macromolecular Materials and Engineering. 306(2):1-14. https://doi.org/10.1002/mame.202000584

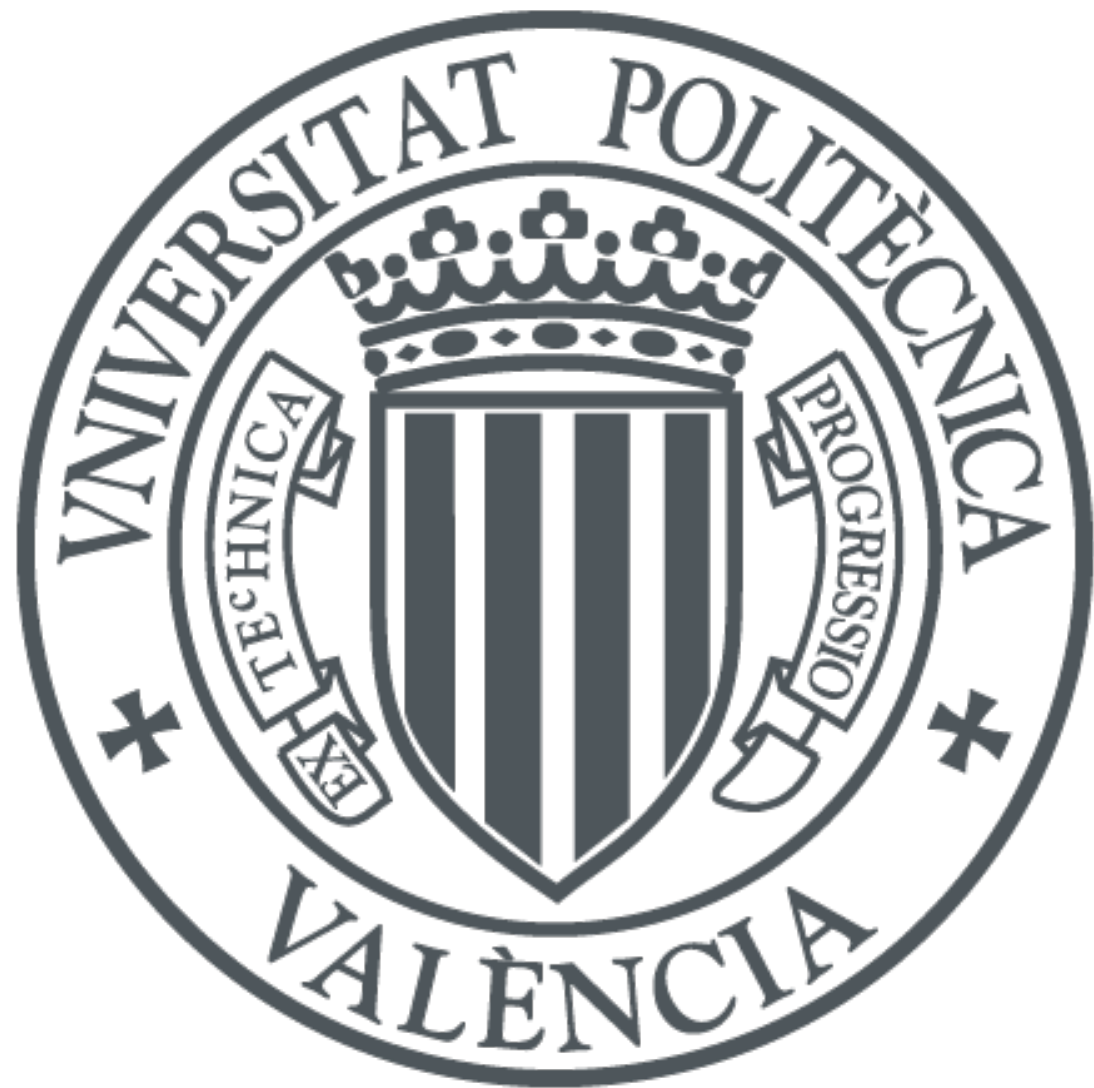

The final publication is available at

https://doi.org/10.1002/mame.202000584

Copyright John Wiley \& Sons

Additional Information

This is the peer reviewed version of the following article: Gisbert, F., García-Bernabé, A., Compañ, V., Martínez-Ramos, C., Monleón, M., Solid Polymer Electrolytes Based on Polylactic Acid Nanofiber Mats Coated with Polypyrrole. Macromol. Mater. Eng. 2021, 306, 2000584, which has been published in final form at https://doi.org/10.1002/mame.202000584. This article may be used for non-commercial purposes in accordance with Wiley Terms and Conditions for Self-Archiving. 


\section{Solid Polymer Electrolytes Based on Polylactic Acid Nanofiber Mats Coated with Polypyrrole}

Fernando Gisbert Roca, Abel García-Bernabé, Vicente Compañ Moreno, Cristina MartínezRamos and Manuel Monleón Pradas*

F. Gisbert Roca, Prof. M. Monleón Pradas, Dr. C. Martínez Ramos

Centro de Biomateriales e Ingeniería Tisular

Universitat Politècnica de València

Camino de Vera s/n, 46022, Valencia, Spain

E-mail: mmonleon@ter.upv.es

Prof. V. Compañ Moreno, Prof. A. García Bernabé

Departamento de Termodinámica Aplicada

Universitat Politècnica de València

Camino de Vera s/n, 46022, Valencia, Spain

Prof. M. Monleón Pradas

CIBER-BBN, Centro de Investigación Biomédica en Red-Bioingeniería, Biomateriales y

Nanomedicina

Spain

Keywords: dielectric properties, ion exchangers, membranes, polyelectrolytes, polypyrroles

The production of electroconductive nanofiber membranes made from polylactic acid (PLA) coated with polypyrrole (PPy) is investigated, performing a scanning of different reaction parameters and studying their physicochemical and dielectric properties. Depending on PPy content a transition between conduction mechanisms is observed, with a temperature-dependent relaxation process for samples without PPy, a temperature-independent conduction process for samples with high contents of PPy and a combination of both processes for samples with low contents of PPy. A homogeneous and continuous coating is achieved from 23 wt $\%$ PPy, observing a percolation effect around $27 \mathrm{wt} \%$ PPy. Higher wt $\%$ PPy allow us to obtain higher conductivities, but PPy aggregates appear from 34\% wt\% PPy. The high conductivity values obtained for electrospun membranes both through-plane and in-plane (above $0.05 \mathrm{~S} / \mathrm{cm}$ and $0.20 \mathrm{~S} / \mathrm{cm}$, respectively, at room temperature) for the highest wt $\%$ of PPy, their porous structure with high specific surface area and their thermal stability below $140^{\circ} \mathrm{C}$ make them candidates for many potential applications as solid polymer electrolytes in, for example, batteries, 
supercapacitors, sensors, photosensors or polymer electrolyte membrane fuel cells (PEMFCs). In addition, the biocompatibility of PLA-PPy membranes expand their potential applications also in the field of tissue engineering and implantable devices.

\section{Introduction}

Intrinsically conductive polymers (ICPs) were discovered by B. Bolto and D. Weiss ${ }^{[1-5]}$ and popularized by Alan J. Heeger, Alan G. MacDiarmid and Hideki Shirakawa ${ }^{[6,7]}$. They have been widely studied during the last decades due to their characteristic physicochemical properties. Within this type of materials, polypyrrole (PPy) has been one of the most studied conductive polymers due to its high electrical conductivity, long-term ambient stability, good biocompatibility, low cost and facile synthesis by chemical or electrochemical polymerization. ${ }^{[8-17]}$ PPy has been used for many commercial applications such as

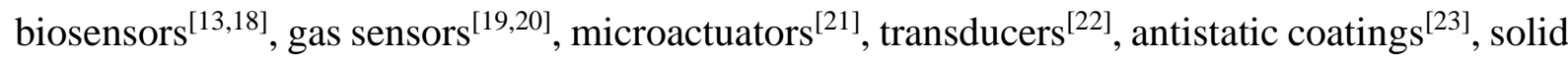
electrolytic capacitors $^{[24,25]}$, polymeric batteries ${ }^{[26]}$, solar cells ${ }^{[27,28]}$, wearable electronics ${ }^{[29,30]}$, electromagnetic interference shielding ${ }^{[31-33]}$, corrosion protection ${ }^{[8,34,35]}$, etc. In addition, PPy has also been applied in fuel cells as catalyst supports for direct methanol fuel cells (DMFCs) ${ }^{[36]}$ and proton-exchange polymer electrolyte membrane fuel cells (PEMFCs) ${ }^{[37]}$, as membranes for $\mathrm{DMFCs}^{[38]}$ and as anodes for microbial fuel cells ${ }^{[39]}$. Furthermore, PPy has become a widely used material in biomedical applications, especially in nerve tissue engineering scaffolds, due to its good biocompatibility and high electrical conductivity. ${ }^{[40-43]}$

As a common characteristic of ICPs, they are semiconductors with wide bandgaps (electrical insulators) in native state and the electrical conductivity is achieved by the incorporation of an anionic compound (dopant) into the polymer matrix. In the doping process an electron is removed from the valence band (p-doping) or added to the conduction band (n-doping) via oxidation/reduction interaction between the conducting polymer and the dopant, generating 
charge carriers in the form of polarons, bipolarons or solitons that move when subjected to an electric field. ${ }^{[17]}$ Different anionic dopants have been studied to improve the electrical conductivity of $\mathrm{PPy}$, such as $\mathrm{Cl}^{-[44]}, \mathrm{SO}_{4}{ }^{2-}{ }^{[44]}, \mathrm{BF}_{4}^{-[}{ }^{-45]}, \mathrm{ClO}_{4}^{-}{ }^{[46,47]}$, dodecylbenzenesulfonate (DBS) ${ }^{[48-51]}$, polystyrene sulfonate (PSS) ${ }^{[52,53]}$ and p-toluenesulfonate (pTS) ${ }^{[54-58]}$. Among all the conducting polymers based on PPy, PPy films doped with pTS (PPy/pTS) have been tested as valid for practical applications due to their good physicochemical properties and long-term stable redox cycling. ${ }^{[59-63]}$ In addition, PPy/pTS films have shown a good ion exchange behavior, presenting both cation and anion transporting properties. ${ }^{[54,64-67]}$ This ion exchange ability is crucial for many practical applications were PPy/pTS films are used as solid polymer electrolytes.

However, the ion diffusion process in the PPy matrix can be blocked when the PPy films present a flat surface with a very compact structure and/or a large thickness, decreasing its electrochemical performance. ${ }^{[44,54]}$ Therefore, with the aim of improving the ion exchange rate of PPy/pTS composites, the thickness of the material must be reduced, and the specific surface area must be increased in order to improve the kinetics of ion exchange. For that reason, in recent years the surface of fibers (both natural and synthetic), fabrics or particles has been coated with conductive PPy, obtaining new composite materials with a high specific surface area that provides a larger interface in sensing, enhances the ionic transportation in electrodes and promotes the cell growth in scaffolds. ${ }^{[29,40,75-77,42,68-74]}$ In addition, it must be considered that PPy is an intractable and brittle solid with poor mechanical processability, which limits its direct application. ${ }^{[14]}$ For that reason, the strategy of coating the surface of other insulating polymers with PPy is interesting in order to exploit both the intrinsic electrical conductivity of PPy and the better mechanical properties of the insulating host polymer. ${ }^{[14,29,40,42,73,74,78]}$

In this study we chose the polylactic acid (PLA) as host polymer of the membranes because it is a low cost, renewable, environmentally friendly and biodegradable substrate. ${ }^{[79,80]}$ According 
to previous studies, the melting peak temperature of PLA is located at around $150-160^{\circ} \mathrm{C}$, starting to melt for temperatures above $140^{\circ} \mathrm{C}^{[81,82]}$. This thermal stability of PLA for temperatures below $140^{\circ} \mathrm{C}$ allows us to use it in almost all the commercial applications ${ }^{[79]}$, while its biocompatibility makes it possible to use the membranes in tissue engineering applications. ${ }^{\left[{ }^{[3,84]}\right.}$ In order to achieve a high specific surface area of the material, PLA was electrospun to obtain nanofiber membranes that present porous structure with small pore size and high pore volume fraction. Then, the electrospun-PLA membrane was coated by in situ chemical polymerization of pyrrole using ferric chloride $\left(\mathrm{FeCl}_{3}\right)$ as oxidant and pTS as dopant. By performing a scan of the reaction parameters of the PPy coating process we obtained membranes with different dielectric properties. A physicochemical and dielectric characterization of these PLA-PPy nanofiber membranes allowed us to study the different electrical behavior of them as the wt $\%$ PPy varies, establishing the range of wt $\%$ PPy were the coating is homogeneous and continuous and the electrical conductivity that is achieved both through-plane and in-plane. This characterization of the membranes will help to choose the appropriate reaction parameters for the desired application, as the electrical conductivity can be adjusted by varying the reaction parameters. These high conductive membranes may have interesting applications in devices where the electrodes are placed both perpendicular to the membrane (through-plane) and in the plane of the membrane (in-plane). For the through-plane disposition, the membranes can be used as solid, low cost, durable and tunable polymer electrolytes for batteries, supercapacitors and fuel cell applications. In addition, the high surface conductivity of the membranes for the in-plane disposition, together with the biocompatibility of both PLA and PPy, also makes them have potential applications in the field of tissue engineering and biomedical implantable devices.

\section{Experimental section}




\subsection{Preparation of PLA nanofiber membranes}

Random and aligned PLA nanofiber membranes were obtained by the electrospinning technique. First, PLA (INGEO 40420 RESINEX) (10\% wt\%) was dissolved in dichloromethane (DCM) / dimethylformamide (DMF) (70/30 v/v) and stirred for 12 hours at room temperature. Then, the solution was introduced into a $12 \mathrm{ml}$ syringe with an internal diameter of $15.77 \mathrm{~mm}$ attached to a precision stainless steel needle with $0.15 \mathrm{~mm}$ of internal diameter (30G). On the one hand, randomly oriented nanofibers were obtained by applying a voltage of $20 \mathrm{kV}$ between the needle tip and the collector, maintaining the flow rate at $4 \mathrm{ml} / \mathrm{h}$ and collecting the nanofibers during 1 hour on a flat plate wrapped with an aluminium foil located $20 \mathrm{~cm}$ from the needle tip. On the other hand, aligned nanofibers were obtained by applying a voltage of $20 \mathrm{kV}$ between the needle tip and the collector, maintaining the flow rate at $3 \mathrm{ml} / \mathrm{h}$ and collecting the nanofibers during 1.5 hours on a round plate wrapped with an aluminium foil with a diameter of $15.5 \mathrm{~cm}$ which centre was located $20 \mathrm{~cm}$ from the needle tip and that was rotating at $32 \mathrm{rps}$. These parameters were chosen from preliminary experiments carried out to establish the optimal conditions (homogeneous fibers, absence of precipitates, etc).

After electrospinning, PLA membranes were air dried for 2 days and introduced in a desiccator with fixed vacuum at room temperature for another 2 days. Finally, PLA membranes were introduced between two glass plates subjected to compression and they underwent a tempering process consisting of stove heating at $90^{\circ} \mathrm{C}$ with $100 \%$ of ventilation for $15 \mathrm{~min}$ and subsequent cooling at $-20^{\circ} \mathrm{C}$ for 2 hours. With this tempering process, a stiffening of the PLA membranes was achieved, which prevented them from wrinkling when they were introduced into water.

\subsection{Preparation of PLA cast membranes}


Non-porous PLA membranes were obtained by the casting technique. First, PLA ( $2 \%$ wt $\%)$ was dissolved in chloroform and stirred for 2 hours at room temperature. Then, the solution was casted into a glass petri dish with ratio between the mass of solution that was casted and the diameter of the petri dish of $1.5 \mathrm{~g} / \mathrm{cm}$. After the casting process, the solution was air dried for 2 days in order to allow the evaporation of chloroform. Finally, the PLA membrane was dried in a desiccator with fixed vacuum at $40^{\circ} \mathrm{C}$ for 2 days.

\subsection{PPy coating}

Electrospun and cast PLA membranes were coated with the conductive polymer PPy via in situ polymerization. As a previous step, electrospun membranes were immersed in deionized water under compression and a fixed vacuum was applied until they stopped floating and, therefore, the introduction of water inside the spaces between nanofibers was achieved, in order to obtain a homogeneous coating of all nanofibers, not only the most superficial ones. Next, each PLA membrane was put into a polypropylene tube with an aqueous solution of pyrrole monomer (Py, Sigma-Aldrich 131709) and sodium para-toluene sulfonate (pTS, Sigma-Aldrich, 152536), followed by ultrasonication for $1 \mathrm{~min}$ in order to allow the membrane to be saturated with Py solution. The membrane was incubated with shaking at $4^{\circ} \mathrm{C}$ for $1 \mathrm{~h}$. The ratio between the membrane area and the final volume of the Py/pTS aqueous solution was $0.6 \mathrm{~cm}^{2} / \mathrm{ml}$ and the different concentrations of Py and pTS that were used are described in Table 1. Then, an aqueous solution of ferric chloride $\left(\mathrm{FeCl}_{3}\right.$, Sigma-Aldrich 157740) was added and incubated with shaking at $4^{\circ} \mathrm{C}$ for $48 \mathrm{~h}$ for the polymerization and deposition of polypyrrole (PPy) on the PLA membrane. The ratio between the membrane area and the final volume of the $\mathrm{FeCl}_{3}$ aqueous solution was $0.6 \mathrm{~cm}^{2} / \mathrm{ml}$ and the different concentrations of $\mathrm{FeCl}_{3}$ that were used are described in Table 1. PPy-coated membranes were washed with deionized water with agitation during $10 \mathrm{~min}$ for three times, ultrasonicated for $30 \mathrm{~min}$ in deionized water for three times and 
washed with pure ethanol during 5 min for two times. Finally, the membranes were dried in a desiccator with fixed vacuum at $40^{\circ} \mathrm{C}$ for 2 days.

Table 1. Reaction parameters used for the PPy coating and mass fraction of PPy for the different PLA cast (C) and electrospun (E) membranes.

\begin{tabular}{ccccccc}
\hline Sample & Coating ratio & $\begin{array}{c}{[\mathrm{Py}]} \\
(\mathrm{mM})\end{array}$ & $\begin{array}{c}{[\mathrm{pTS}]} \\
(\mathrm{mM})\end{array}$ & $\begin{array}{c}{\left[\mathrm{FeCl}_{3}\right]} \\
(\mathrm{mM})\end{array}$ & $\begin{array}{c}\text { Reaction } \\
\text { time } \\
(\mathrm{h})\end{array}$ & $\begin{array}{c}\text { PPy mass } \\
\text { fraction } \\
(\%)\end{array}$ \\
\hline C1 & CR1 & 7.0 & 7.0 & 19.0 & 48.0 & $0.6 \pm 0.1$ \\
C2 & CR2 & 14.0 & 14.0 & 38.0 & 48.0 & $2.0 \pm 0.1$ \\
E4 & CR1 & 7.0 & 7.0 & 19.0 & 48.0 & $4.0 \pm 2.0$ \\
E13 & CR1.5 & 10.5 & 10.5 & 28.5 & 48.0 & $13.0 \pm 3.0$ \\
E18 & CR2 & 14.0 & 14.0 & 38.0 & 48.0 & $18.2 \pm 0.7$ \\
E23 & CR2.5 & 17.5 & 17.5 & 47.5 & 48.0 & $23.0 \pm 5.0$ \\
E27 & CR3 & 21.0 & 21.0 & 57.0 & 48.0 & $27.0 \pm 2.0$ \\
E34 & CR4 & 28.0 & 28.0 & 76.0 & 48.0 & $34.0 \pm 4.0$ \\
\hline
\end{tabular}

\subsection{Characterization of PLA-PPy composites}

\subsubsection{Porosity and specific surface area of electrospun membranes}

The porosity $(\pi)$ of electrospun membranes was calculated using Equation 1, where $\varphi_{P L A}$ is the density of PLA as a non-porous film and $\varphi_{E M}$ is the density of the electrospun membranes $(n=5)$.

$\pi=\frac{\varphi_{\mathrm{PLA}}-\varphi_{\mathrm{EM}}}{\varphi_{\mathrm{PLA}}} \cdot 100$

To obtain $\varphi_{E M}$, Equation 2 was applied, where $m, V, e$ and $A$ are, respectively, the mass, the volume, the thickness and the area of electrospun membranes. 
$\varphi_{\mathrm{EM}}=\frac{m}{\mathrm{~V}}=\frac{m}{e \cdot A}$

The specific surface area (SSA) of electrospun membranes was calculated following

Equation 3, where $r$ is the average radius of the nanofibers, $n_{N F}$ is the number of nanofibers, $V_{1 N F}$ is the volume of one nanofiber, $\varphi_{P L A}$ is the density of PLA as a non-porous film and $L$, $m$ and $V$ are, respectively, the length, the mass and the volume of electrospun membranes.

$\mathrm{SSA}=\frac{2 \cdot \pi \cdot r \cdot L \cdot n_{N F}}{\mathrm{~m}}=\frac{2 \cdot \pi \cdot r \cdot L \cdot \frac{V}{V_{1 N F}}}{\mathrm{~m}}=\frac{2 \cdot \pi \cdot r \cdot L \cdot \frac{\frac{m}{\varphi_{P L A}}}{\pi \cdot r^{2} \cdot L}}{\mathrm{~m}}=\frac{2}{\varphi_{P L A} \cdot r}$

The average radius of nanofibers (r) was considered as $381 \pm 80 \mathrm{~nm}$ (obtained from FESEM images using the ImageJ/FIJI image processing software $\left.{ }^{[85]}\right)$ and the density of PLA $\left(\varphi_{P L A}\right)$ was considered as $1.25 \mathrm{~g} / \mathrm{cm}^{3[86]}$.

\subsubsection{Mass fraction of PPy}

The mass fraction of PPy deposited on PLA electrospun membranes was measured by weighing the PLA membranes before and after covering them with PPy using a precision balance (AX205, Mettler-Toledo Inc., sensibility of 0,01 mg) and applying Equation 4.

$\omega_{\text {PPy }}=\frac{m_{P P y}}{m}=\frac{m_{f}-m_{0}}{m_{f}}$

\subsubsection{Morphological characterization by field emission scanning electron microscopy} (FESEM)

For the characterization of the surface morphology of membranes, a field emission scanning electron microscope (FESEM; ULTRA 55, ZEISS Oxford Instruments) was used. The 
preparation of the samples consisted primarily in a desiccation under vacuum conditions during the 24 hours prior to the test to avoid interferences due to evaporated water. Subsequently samples were placed on a carbon tape and a carbon bridge was created between the sample and the carbon tape. Finally, samples were coated with a thin layer of platinum. The voltage used was $2 \mathrm{kV}$.

\subsubsection{Fourier transform infrared spectroscopy (FTIR) analysis}

FTIR spectra of membranes were obtained using a Cary 630 FTIR (Agilent Technologies) in the attenuated total reflection mode (ATR). The spectra resulted from averages of 24 scans at 4 $\mathrm{cm}^{-1}$ resolution, between 400 and $4000 \mathrm{~cm}^{-1}$. Three different samples of each material were studied, plotting the most representative curve for each one.

\subsubsection{Thermogravimetric analysis (TGA)}

A thermogravimetric analyzer (TGA/SDTA 851 Mettler-Toledo operated using the STARexx software) was used to study the thermal degradation and composition of the materials. Samples with a mass of approximately $2 \mathrm{mg}$ were processed, monitoring the mass loss while heating up to $800^{\circ} \mathrm{C}$ at a rate of $10^{\circ} \mathrm{C} / \mathrm{min}$ under a positive nitrogen $\left(\mathrm{N}_{2}\right)$ flow of $20 \mathrm{ml} / \mathrm{min}$. As a result, thermograms in which the mass loss of the sample is represented as a function of temperature were obtained. Three different samples of each material were studied, plotting the most representative curve for each one. The mass fraction of PPy of the different PLA-PPy samples was calculated from TGA residues by applying Equation 5.

$m_{\text {sample }}=m_{P L A} \cdot\left(1-\omega_{P P y}\right)+m_{P P y} \cdot \omega_{P P y}$ 
The complex conductivity and permittivity of the compounds was measured by impedance spectroscopy at several temperatures within the $273 \mathrm{~K}\left(0^{\circ} \mathrm{C}\right)-333 \mathrm{~K}\left(60^{\circ} \mathrm{C}\right)$ range and frequency window $10^{-1}<\mathrm{f}<10^{7} \mathrm{~Hz}$ using a Novocontrol Broadband Dielectric Spectrometer (Hundsangen, Germany) integrated with an SR 830 lock-in amplifier with an Alpha dielectric interface. The experiments were performed with $100 \mathrm{mV}$ amplitude. The samples were placed between two gold electrodes. During the conductivity measurements, temperature was kept isothermally or changed stepwise within the entire temperature range controlled by a nitrogen jet (QUATRO from Novocontrol) with a temperature error of $0.1 \mathrm{~K}$ during every single scan in frequency.

\section{Results and discussion}

\subsection{PPy coating characterization and morphological properties}

First, we proceeded to cover with PPy non-porous films of PLA created by casting following 2 different Coating Ratios (CR1 and CR2), as an idealized control without air. Since the amount of PPy deposited was very small, the mass fraction of PPy was obtained from the TGA residues (Figure S5). As can be seen in Table 1 and Figure S1, using non-porous PLA films entails that the mass fraction of PPy deposited on the membranes is very small: $1 \%$ for samples coated using CR1, hereinafter named as C1 (Casting $1 \mathrm{wt} \%$ PPy), and 2\% for samples coated using CR2, hereinafter named as C2 (Casting $2 \mathrm{wt} \%$ PPy). This occurs because the films do not present any porosity and, therefore, the PPy is not able to penetrate inside the film and only remains on its surface. As can be observed in Figure S1, there is a linear relationship between the mass fraction of PPy and the concentration of Py used for the coating.

From the FESEM images (Figure S2) it can be observed that the Cast PLA film (CPLA) is nonporous, with a flat and smooth surface without porosity. However, when the film has $1 \mathrm{wt} \%$ 
PPy $(\mathrm{C} 1)$, a rougher surface is observed due to the presence of PPy. This roughness increases when the mass fraction of PPy rises to $2 \mathrm{wt} \%$ (C2), forming PPy aggregates.

Next, we proceeded to cover with PPy the electrospun membranes of PLA following 6 different coating ratios (CR1, CR1.5, CR2, CR2.5, CR3 and CR4). Since the amount of PPy deposited was sufficiently large, the mass fraction of PPy was obtained by weighing the membranes before and after their coating with PPy. As can be seen in Table 1 and Figure 1, using electrospun membranes instead of non-porous films entails that the amount of PPy deposited is much higher, becoming 4 times higher for CR1 and 9 times higher for CR2, thanks to the greater specific surface area and porosity of electrospun membranes (specific surface area of $4.2 \pm 0.9 \mathrm{~m}^{2} / \mathrm{g}$ and porosity of $67 \pm 3 \%$ ). Electrospun membranes with both random and aligned orientation of the nanofibers were coated with PPy, without observing significant differences in the amount of PPy deposited. As can be observed in Figure 1, there is a linear relationship between the mass fraction of PPy and the concentration of Py used for the coating.

From the FESEM images of electrospun membranes with random orientation of the nanofibers (Figure 2) it can be observed that the Electrospun-PLA membrane (EPLA) presents nanofibers with a flat and smooth surface. However, when the PLA nanofibers are coated with different amounts of PPy, changes appear in their surface morphology. When the mass fraction of PPy is low (Electrospun membranes with 4 wt\% PPy (E4), 13 wt\% PPy (E13) and 18 wt\% PPy (E18), coated using CR1, CR1.5 and CR2, respectively), the layer of PPy deposited on the nanofibers of PLA is not homogeneous and presents discontinuities, so that there are accumulations of PPy isolated from each other. These discontinuities in the PPy coating are more significant for the samples with the least amount of PPy (E4), causing the deposited PPy mass fraction to move significantly away from the linear trend followed by the other samples as the Py concentration increases (Figure 1B). For an intermediate mass fraction of PPy (Electrospun membranes with 23 wt\% PPy (E23) and 27 wt\% PPy (E27), coated using CR2.5 
and CR3, respectively), the layer of PPy deposited on the nanofibers of PLA is continuous and homogeneous, without aggregates of consideration. Here all the PPy is in contact with each other, without forming isolated accumulations. Finally, when the mass fraction of PPy is high (Electrospun membranes with 34 wt\% PPy (E34), coated using CR4), the continuous and homogeneous coating is maintained but aggregates of PPy are formed.

The detail of a cross-section of the PPy coating is indicated by an arrow in Figure $\mathbf{S 3}$ for E23, where the coating is continuous and homogeneous without forming PPy aggregates. An analysis of the image allows to know the thickness of the PPy coating, which is around $100 \mathrm{~nm}$.

The same effect of PPy coating seen before for electrospun membranes with a random orientation of the nanofibers can be observed for electrospun membranes with an aligned orientation of the nanofibers (Figure 3). Low mass fractions of PPy entail an inhomogeneous coating of the nanofibers (E4 and E18), with chipping and with areas not covered with PPy. However, higher concentrations (E27 and E34) achieve a homogenous and continuous coating of the nanofibers. The highest concentration (E34) also presents PPy aggregates.

\subsection{Fourier transform infrared spectra (FTIR)}

First, cast-PLA films (CPLA) and electrospun-PLA membranes (EPLA) were analyzed and characteristic peaks corresponding to PLA were observed: $2995 \mathrm{~cm}^{-1}\left(-\mathrm{CH}_{3}\right.$ asymmetric stretching), $2944 \mathrm{~cm}^{-1}$ (- $\mathrm{CH}_{3}$ symmetric stretching), $1752 \mathrm{~cm}^{-1}$ (C=O stretching), $1181 \mathrm{~cm}^{-1}$ (CO-C stretching) and $1084 \mathrm{~cm}^{-1}$ (C-O stretching). ${ }^{[87,88]}$ These characteristic peaks of PLA are indicated in Figure 4A for EPLA. Powder of pure PPy doped with pTS (PPy) was also analysed and peaks corresponding both to PPy and pTS appeared (Figure 4B). PPy characteristic peaks where found at $3375 \mathrm{~cm}^{-1}$ (N-H bond), $1643 \mathrm{~cm}^{-1}$ ( $\mathrm{C}=\mathrm{C}$ bond), $1532 \mathrm{~cm}^{-1}$ and $1451 \mathrm{~cm}^{-1}$ (fundamental vibrations of PPy ring), $1291 \mathrm{~cm}^{-1}$ (C-H deformation) and $773 \mathrm{~cm}^{-1}$ (C-N bond) ${ }^{\text {[89] }}$, while pTS characteristic peaks where found at $1150 \mathrm{~cm}^{-1}(\mathrm{C}-\mathrm{H}$ in-plane bending vibration), 
$1126 \mathrm{~cm}^{-1}$ (stretching vibration of $-\mathrm{SO}_{3}{ }^{-}$groups), $1010 \mathrm{~cm}^{-1}\left(\mathrm{~S}=\mathrm{O}\right.$ stretching vibration of $-\mathrm{SO}_{3}{ }^{-}$ groups), $812 \mathrm{~cm}^{-1}$ (C-H stretch of the para-positioned $-\mathrm{CH}_{3}$ group), $676 \mathrm{~cm}^{-1}$ (C-H out-of-plane bending vibration) and $563 \mathrm{~cm}^{-1}$ (benzene ring C-C vibrations) ${ }^{[66]}$.

Then, the presence of the PPy coating on PLA-PPy composites was corroborated by FTIR (Figure S4 for cast films and Figure 5 for electrospun membranes). As can be observed, both cast PLA-PPy films and PLA-PPy electrospun membranes maintain the characteristic peaks of PLA $\left(2995 \mathrm{~cm}^{-1}, 2944 \mathrm{~cm}^{-1}, 1752 \mathrm{~cm}^{-1}, 1181 \mathrm{~cm}^{-1}\right.$ and $1084 \mathrm{~cm}^{-1}$, marked with green vertical lines), even though their intensity decreases as the amount of PPy increases. Regarding the PPy and pTS characteristic peaks, some of them are hidden by PLA peaks, but others are clearly visible (marked with red and blue vertical lines for PPy and pTS, respectively). For both cast and electrospun PLA-PPy composites, the peak corresponding to the fundamental vibration of the PPy ring at $1532 \mathrm{~cm}^{-1}$ is clearly visible, but slightly shifted towards higher wavelengths as the amount of PPy decreases. For PLA-PPy electrospun membranes with a higher content of PPy (above $23 \mathrm{wt} \%$ ), the PPy characteristic peaks at $1291 \mathrm{~cm}^{-1}$ and $773 \mathrm{~cm}^{-1}$ are also visible. Regarding the pTS characteristic peaks, those located at $676 \mathrm{~cm}^{-1}$ and $563 \mathrm{~cm}^{-1}$ are clearly visible both for cast and electrospun PLA-PPy samples, while the peak located at $1010 \mathrm{~cm}^{-1}$ is visible for PLA-PPy electrospun membranes with a higher amount of PPy. As the mass fraction of PPy increases in the samples, the intensity of the peaks corresponding to the PLA decreases, while the intensity of the peaks corresponding to the PPy and pTS increases, indicating the greater presence of PPy and pTS on the surface of PLA nanofibers.

\subsection{Thermogravimetric analysis (TGA)}

The degradation temperature and thermal stability of PLA, PLA-PPy and PPy samples, as well as the presence of the PPy coating on PLA-PPy materials was studied by a thermogravimetric analysis (TGA). Regarding the cast films (Figure S5), a first mass loss between $100^{\circ} \mathrm{C}$ and 
$170^{\circ} \mathrm{C}$ can be observed for $\mathrm{C} 2$ that does not occur for either CPLA or for $\mathrm{C} 1$, indicative of the higher presence of PPy. The study of the TGA residues shows that, although the amount of PPy deposited on the PLA film is small, it is enough to observe a greater residue as the amount of PPy increases. These residues were used to obtain the mass fraction of PPy present on PLAPPy cast films applying Equation 5.

Regarding the electrospun membranes (Figure 6), a first mass loss between $50^{\circ} \mathrm{C}$ and $100^{\circ} \mathrm{C}$ is observed for PLA-PPy composites that increases as more PPy contains the sample. As previously observed for pTS doped PPy, this is mainly due to evolution of adsorbed pTS and $\mathrm{H}_{2} \mathrm{O} .{ }^{[90]}$ It has also been observed that the thermal decomposition of pTS doped PPy starts above $180^{\circ} \mathrm{C}^{[90]}$, leading to the increased mass loss that can be observed for the PPy curve above this temperature. This leads to the mass loss observed for the PLA-PPy composites above this temperature, which increases proportionally to the amount of PPy present in the samples. A delay in thermal degradation can also be observed as more PPy contains the sample. For example, EPLA and E4 suffer the loss of $30 \%$ of their mass at $350^{\circ} \mathrm{C}$, while E34 suffers it at $360^{\circ} \mathrm{C}$. This indicates that the PPy coating of PLA nanofibers is continuous and homogeneous, being thicker as the mass fraction of PPy increases.

The study of TGA residues of PLA-PPy electrospun membranes clearly indicates the presence of the PPy coating, since the residues increase as more PPy contains the sample. These residues were used to obtain the samples composition by applying Equation 5. When we compared the mass fraction of PPy obtained by TGA residues with the one obtained by weighing the samples before and after covering them with PPy (Figure S6), an oversizing of 50\% of the mass fraction of PPy when using TGA residues. It could be produced by a greater retention of PLA volatiles by the PPy coating, so the extra residue is formed by both PLA and PPy and not only by PPy.

\subsection{Electrical characterization}


The electrical behavior of PLA-PPy materials was studied for both through-plane and in-plane applications.

\subsubsection{Through-plane electrical measurements}

Electrospun membranes with a random orientation of the nanofibers (E4, E13, E18, E23, E27 and E34) were studied for through-plane applications. Cast films (C1 and C2) through-plane electrical behavior was also studied as a control without air. Through-plane electrical behavior was studied by electrochemical impedance spectroscopy (EIS).

\section{PLA-PPy cast films}

EIS measurements were carried out on PLA (CPLA) and PLA-PPy (C1 and C2) cast films in dry conditions at several temperatures to obtain the conductivity of the samples. The experimental data were analyzed in terms of the complex dielectric permittivity function, $\varepsilon^{*}(\omega, T)$, and the complex conductivity $\sigma^{*}(\omega, T)=j \cdot \omega \cdot \varepsilon_{0} \cdot \varepsilon^{*}(\omega, T)$ where $j$ is the imaginary unity, $\varepsilon_{0}$ is the vacuum permittivity and $\omega$ the angular frequency of the applied electric field $(\omega=2 \cdot \pi \cdot f)$.

Figure 7 presents the spectra of the real and imaginary part of the complex permittivity, $\mathcal{E}^{\prime}$ and $\varepsilon "$, respectively, for each one of the samples at different temperatures in the interval from $0^{\circ} \mathrm{C}$ to $60^{\circ} \mathrm{C}$. Different behavior is observed when we compare the PLA sample with the PLA-PPy samples with different mass fractions of PPy (1\% and 2\%). We can observe a decreasing of effective permittivity as frequency increases. This is because at low frequencies the dipoles that are formed and the charges in the polymer chains can follow the electric field below the electrode polarization (EP) effect, but when the frequency increases both dipoles and polymer chains have more difficult to follow the electric field and then the effective permittivity decreases. For example, for $f=10^{7} \mathrm{~Hz}$, while the real part of the permittivity for PLA 
membranes varies with temperature between 6.5 at $0^{\circ} \mathrm{C}$ to 7.2 at $60^{\circ} \mathrm{C}$, for the PLA-PPy membranes it is practically independent of temperature, being around 3.7 and 6.4 for $\mathrm{C} 1$ and C2, respectively.

Regarding the loss permittivity, $\mathcal{E}$ ', it presents a relaxation process for CPLA and C1 films when the temperature approaches to the glass transition temperature $\left(\mathrm{T}_{\mathrm{g}}\right)$ of PLA. However, when the amount of PPy increases in the matrix of PLA (C2), the relaxation disappears because the conduction process generated inside the membrane is dominant in comparison with the polymer relaxation. The analysis of this relaxation process allows us to observe that it starts at $45^{\circ} \mathrm{C}$, so the relaxation is not noticeable below this temperature, at least in the range of frequencies studied.

The dielectric spectra were fitted using a Havriliak-Negami function given by Equation 6.

$\varepsilon^{*}=\varepsilon_{\infty}+\frac{\Delta \varepsilon}{\left[1+(j \omega \tau)^{\alpha}\right]^{\beta}}$

In Figure 8 we can see an example of the fitting. The values of the parameters for the temperatures where the relaxation is present are plotted in Figure 9A. From this plot we can see for CPLA that $\varepsilon_{\infty}, \alpha$ and $\beta$ are constants, while $\Delta \varepsilon$ increases slightly with temperature. Moreover, the relaxation peaks shift with the increase in temperature towards higher frequencies. There is a characteristic frequency for each temperature for CPLA, showing that the relaxation time decreases as temperature increases (Figure 9B).

Figure 9A also shows the variation of the fitting parameters with temperature for the sample C1. In our sample we have obtained that $\varepsilon_{\infty}, \alpha$ and $\beta$ are constants being the values of $\varepsilon_{\infty}$ and $\alpha$ smaller than the CPLA ones. From Figure 9B, we observe for C1 that the incorporation of PPy produces an additional relaxation process with a relaxation time that is practically independent of temperature, indicative of its predominantly conductive nature, preserving the 
temperature-dependent relaxation processes previously observed for CPLA. Such relaxations observed in CPLA and $\mathrm{C} 1$ films at sub- $\mathrm{T}_{\mathrm{g}}$ temperatures usually originate from molecular motions that are restricted to the scale of few bond lengths.

The bulk conductivity was obtained from the Bode diagrams in the interval of temperatures from $0^{\circ} \mathrm{C}$ to $60^{\circ} \mathrm{C}$. Figure 10 shows the Bode diagrams of the CPLA, C1 and C2 samples. For CPLA we observe the behavior of a pure capacitor, as the conductivity increases linearly with the frequency with a slope practically equal the unit, and the phase angle is between $-85^{\circ}$ and $90^{\circ}$. A similar behavior is observed for $\mathrm{C} 1$.

For the other samples (CPLA and C1) the behavior is, in agreement with our results, completely capacitive. Moreover, the capacity of the samples is dependent of the temperature. For example, for CPLA the capacity increases from $30 \mathrm{pF}$ at $0^{\circ} \mathrm{C}$ to $55 \mathrm{pF}$ at $60^{\circ} \mathrm{C}$, however at $40^{\circ} \mathrm{C}$ we can observe a behavior at low temperatures where the capacity is practically constant, and an abrupt change of slope at $40^{\circ} \mathrm{C}$ increasing the capacity from $31 \mathrm{pF}$ to $55 \mathrm{pF}$. For the sample $\mathrm{C} 1$ we can observe an increasing from $34 \mathrm{pF}$ at $0^{\circ} \mathrm{C}$ until $38 \mathrm{pF}$ at $40^{\circ} \mathrm{C}$, to then decrease until $29 \mathrm{pF}$ at $60^{\circ} \mathrm{C}$. Finally, for the sample $\mathrm{C} 2$ the capacity increase with temperature from $40 \mathrm{pF}$ at $0^{\circ} \mathrm{C}$ until $51 \mathrm{pF}$ at $60^{\circ} \mathrm{C}$. For such sample we also observe a similar increasing around $35^{\circ} \mathrm{C}$.

However, when the mass fraction of PPy increases, such is the case of the sample C2, the spectra reveals that the real part of the conductivity increases with the frequency and tends to a constant value when the phase angle, $\varphi$, reaches a maximum, for each temperature. We also can observe that in the range of high frequencies the conductivity varies linearly (slope $\sim 1$ ) with the frequency, following a capacitive behavior. The length of the plateau in the Bode diagram of $\mathrm{C} 2$ increases as temperature increases until a critical frequency fc dependent on temperature is reached, at which $\log |\sigma|$ collapses along a straight line with a slope equal to 1 . This is a typical behavior of a parallel $\mathrm{R}_{0} \mathrm{C}$ circuit, where at high frequencies the modulus of the impedance can be expressed as Equation 7. 
$\lim _{\omega \rightarrow \infty} \log \left|Z^{*}(\omega)\right|=\lim _{\omega \rightarrow \infty} \log \left|\frac{R_{0}}{1+j \omega R_{0} C}\right| \cong \log \left(\frac{1}{C \omega}\right)$

From the straight line of the plot of $\log |Z|$ vs. $\log \omega$, we can obtain from the intercept the capacity of the sample. On the other hand, at low frequencies where $\omega C<<1$, the limit of Equation 7 is the bulk resistance $\left(\mathrm{R}_{0}\right)$. This resistance is related with the DC-conductivity through $\sigma=L /\left(R_{0} A\right)$, being $\mathrm{L}$ and $\mathrm{A}$ the sample thickness and surface area sandwiched between the two electrodes, respectively. At the same time the phase angle increases from $-90^{\circ}$ to $-5^{\circ}$. However, above the critical frequency, $f_{c}=\omega_{c} / 2 \pi$, being $\omega_{c} \geq 1 /\left(R_{0} C\right)$, the impedance is completely capacitive and $\left|Z^{*}(\omega)\right| \propto \omega^{-1}$, in agreement with the results shown for $\mathrm{C} 2$.

The DC-conductivity of the sample $\mathrm{C} 2, \sigma_{D C}$, can be extracted from the plateau in the moderate frequency range (Figure S7), reaching a conductivity value of $4.6 \cdot 10^{-9} \mathrm{~S} / \mathrm{cm}$ when setting the frequency at $15.4 \mathrm{~Hz}$ and the temperature at $30^{\circ} \mathrm{C}$. Furthermore, the frequency value where the plateau is reached is shifted to higher frequencies by increasing the temperature, as consequence of the thermally activated nature of the charge transport. However, at moderate and low frequencies the conductivity decreases from $\sigma_{D C}$. The deviation from the plateau is attributed to the electrode polarization resistance, which results from the blocking of charge carriers at the electrodes. ${ }^{[91-96]}$

\section{PLA-PPy electrospun membranes}

In this case the EIS measurements were carried out on PLA (EPLA) and PLA-PPy (E4, E13, E18, E23, E27 and E34) electrospun membranes with a random orientation of the nanofibers in dry conditions at different temperatures $\left(0^{\circ} \mathrm{C}\right.$ to $\left.60^{\circ} \mathrm{C}\right)$ in order to obtain information about the conductivity of the samples. Data for the real part of the conductivity was analyzed in terms of 
the corresponding Bode diagrams, where variations of the conductivity with the frequency for all the PLA and PLA-PPy electrospun membranes are shown in Figure 11 (EPLA, E4, E13 and E18) and Figure S8 (E23, E27 and E34). A close inspection of these figures shows that, in the case of EPLA, a plateau of the real part of the conductivity is not observed, presumably, because it is at very low frequencies, outside the range of measurement of our experiments, showing a dielectric behavior of PLA membranes. For such PLA membranes, our results show straight lines with slope ca. 1, indicating that the material is purely capacitor, where the values of the geometrical capacitance (C) are around 40pF. For PLA-PPy membranes with a content in PPy equal to $4 \%$ wt (E4), we observe that the conductivity is practically constant in the range of frequencies between $0.1 \mathrm{~Hz}$ and $10^{3} \mathrm{~Hz}$, depending of temperature, showing a cut-off frequency where it starts increasing linearly with the frequency, as if the sample was a capacitor. However, when the mass fraction of PPy is greater or equal to 13\%wt (E13, E18, E23, E27 and E34), the real part of the conductivity is constant for all range of frequencies $\left(0.1 \mathrm{~Hz}\right.$ to $\left.10^{6} \mathrm{~Hz}\right)$, meaning that the impedance has only a resistive contribution and its value represents the electrical conductivity of the nanocomposite. This behavior is the typical demeanor of a conductive material.

A quantitative analysis of the conductivity with temperature for the PLA-PPy nanocomposites can be observed in Figure 12. A comparison between the different nanocomposites shows that the conductivity $\left(\sigma_{D C}\right)$ is a function of the amount of PPy that we have incorporated on the surface of the nanofibers of PLA, so the conductivities increase when the amount of PPy increases (Figure 12A and 12C), observing an Arrhenius behavior for all the nanocomposites (Figure 12A). For example, the conductivities obtained from the Bode diagrams at $30^{\circ} \mathrm{C}$ with a fixed frequency of $15.4 \mathrm{~Hz}$ were $1 \cdot 10^{-11} \mathrm{~S} / \mathrm{cm}, 6.3 \cdot 10^{-9} \mathrm{~S} / \mathrm{cm}, 2.7 \cdot 10^{-3} \mathrm{~S} / \mathrm{cm}, 3.5 \cdot 10^{-3} \mathrm{~S} / \mathrm{cm}$, 9.6 $10^{-3} \mathrm{~S} / \mathrm{cm}, 3.9 \cdot 10^{-2} \mathrm{~S} / \mathrm{cm}$ and $5.2 \cdot 10^{-2} \mathrm{~S} / \mathrm{cm}$ for EPLA, E4, E13, E18, E23, E27 and E34, respectively. This is in accordance with the conductivities obtained in other studies where a 
combination of an insulting polymer and PPy is employed in order to obtain electrically conductive electrospun membranes, where similar conductivities are obtained ${ }^{[41,97,98]}$ A similar trend is observed for all the range of temperatures, but with an increase in conductivity (Figure $12 \mathrm{C})$. This suggests that the interaction between the ions and the nanofiber polymer matrix may play an important role in determining the relationship between the ionic transport and the structural relaxation in terms of the temperature and PPy incorporated to the composite.

If we compare these conductivity values with those obtained for cast membranes ( $\mathrm{C} 1$ and $\mathrm{C} 2$ ) we observe that, for a coating ratio of 1 (CR1), a conductivity value of $5.46 \cdot 10^{-11} \mathrm{~S} / \mathrm{cm}$ is achieved for cast films, while a conductivity value of $6.3 \cdot 10^{-9} \mathrm{~S} / \mathrm{cm}$ is achieved with electrospun membranes (115 times higher). The same trend is observed with the coating ratio 2 (CR2), since 4.6 $10^{-9} \mathrm{~S} / \mathrm{cm}$ are achieved with non-porous films and $3.5 \cdot 10^{-3} \mathrm{~S} / \mathrm{cm}$ are achieved with electrospun membranes (more than $7.6 \cdot 10^{5}$ times higher).

Therefore, a greater conductivity is achieved when using electrospun membranes instead of non-porous films for the same coating parameters thanks to the greater specific surface area and greater porosity of electrospun membranes. They allow a greater PPy deposition as well as a simpler entry of PPy to the core of the material, connecting the two external surfaces of the membrane with PPy. The improved electrical behavior of electrospun membranes is also observed for the activation energy (Figure 12B), which is almost 6 times higher for $\mathrm{C} 2$ than for E18 (cast and electrospun samples coated with CR2). A lower activation energy is indicative of a greater ease of transport of electric charges.

In order to calculate the intrinsic conductivity of PPy, we proceeded to divide the apparent conductivity values between the volumetric fraction of PPy (Figure 12D), which was obtained by applying Equation 8 . 
$\emptyset_{P P y}=\frac{V_{P P y}}{V_{P P y}+V_{P L A}}=\frac{\frac{m \cdot \omega_{P P y}}{\varphi_{P P y}}}{\frac{m \cdot \omega_{P P y}}{\varphi_{P P y}}+\frac{m \cdot \omega_{P L A}}{\varphi_{P L A}}}=\frac{\frac{\omega_{P P y}}{\varphi_{P P y}}}{\frac{\omega_{P P y}}{\varphi_{P P y}}+\frac{1-\omega_{P P y}}{\varphi_{P L A}}}$

This allows us to observe a percolation effect from E27, so the conductivity for E34 does not increase, as it does with the values of apparent conductivity, and remains constant with an approximate value of $0.17 \mathrm{~S} / \mathrm{cm}$ for a frequency of $15.4 \mathrm{~Hz}$ and a temperature of $30^{\circ} \mathrm{C}$, which is consistent when compared with the DC conductivity obtained for pure PPy in other studies. ${ }^{[99,100]}$ This is indicative that from $27 \mathrm{wt} \%$ PPy there is a perfect continuity between the PPy grains. The homogeneity and continuity of the PPy coating can also be observed with the activation energy (Figure 12B), since it decreases as the mass fraction of PPy increases, until it stabilizes for the higher contents of PPy.

\subsubsection{In-plane electrical measurements}

Electrospun membranes with an aligned orientation of the nanofibers (E4, E18, E27 and E34) were studied for in-plane applications. In-plane electrical behavior was studied by measuring superficially the circulating electric current (DC) when applying a known voltage. This allowed us to calculate the apparent surface electrical resistance of the materials (R) by Ohm's law, normalizing by the distance between contacts (1), at room temperature (Figure 13A). As can be observed, the effect of the amount of PPy deposited on the surface of the PLA membrane is very remarkable, so the surface electrical resistance of the materials decreases following a potential function when the wt $\%$ PPy increases.

In addition, after measuring the cross section of the membranes (S), the in-plane apparent DCconductivity $\left(\sigma_{D C, I P}\right)$ of the materials could be obtained by Equation 9.

$\sigma_{D C, I P}=\frac{l}{R \cdot S}$ 
As can be observed in Figure 13B, there is a relationship between the electrical conductivity and the mass fraction of PPy very similar to that obtained for through-plane measurements (Figure 12C). The conductivity increases rapidly and practically linearly from $20 \mathrm{wt} \%$ of PPy, having very small conductivities for PPy mass fractions below this value. The in-plane conductivity values are approximately 4 times higher than those measured through-plane. This means that the charge carriers find less resistance when traveling superficially than when travelling across the material. In addition, the aligned disposition of the nanofibers aims to improve the conductivity for in-plane applications.

Finally, the intrinsic conductivity of PPy was calculated by applying Equation 10.

$\sigma_{P P y}=\frac{1}{\frac{R}{l} \cdot A_{P P y}}=\frac{1}{\frac{R}{l} \cdot \frac{V_{P P y}}{l}}=\frac{l^{2}}{R \cdot V_{P P y}}=\frac{l^{2}}{R \cdot \frac{m_{P P y}}{\varphi_{P P y}}}==\frac{l^{2}}{R \cdot \frac{m \cdot \omega_{P P y}}{\varphi_{P P y}}}=\frac{l^{2} \cdot \varphi_{P P y}}{R \cdot m \cdot \omega_{P P y}}$

As can be observed in Figure 13C, a behavior like that previously observed for the throughplane measurements (Figure 12D) was obtained. There is a percolation phenomenon from 27 wt\% PPy, indicating a perfect continuity between PPy grains from this mass fraction value of PPy. The PPy conductivities obtained in-plane are approximately 6 times higher than those obtained through-plane, following the trend observed with the apparent conductivities.

\section{Conclusions}

In this work, both non-porous films and electrospun membranes made of PLA were coated with different mass fractions of PPy. Its physicochemical and dielectric characterization allowed us to conclude that the use of nanofiber membranes entails a greater PPy deposition due to their greater specific surface area and porosity, leading to higher conductivity values. The dielectric measurements for both cast films and electrospinning membranes showed a transition between 
conduction mechanisms depending on PPy content. While for samples without PPy a temperature-dependent relaxation process appeared as the temperature approached to the glass transition temperature of PLA, for samples with a high content of PPy a temperatureindependent conduction process was present, hiding the polymer relaxation. For samples with a low content of PPy, an intermediate behavior was observed, with a combination of both processes. Both FESEM and EIS analysis allowed us to conclude that a continuous and homogeneous coating of PLA nanofibers with PPy is achieved from 23wt\% PPy. We can also conclude that the electrical conductivity of PLA-PPy electrospun membranes depends directly on the amount of PPy deposited on the PLA nanofibers. Therefore, greater conductivities are achieved as wt $\%$ PPy increases where a percolation effect was observed around $27 \mathrm{wt} \%$ PPy for E27 membranes, reaching conductivity values above $0.05 \mathrm{~S} / \mathrm{cm}$ for through-plane applications and above $0.20 \mathrm{~S} / \mathrm{cm}$ for in-plane applications for the highest wt\% PPy. This indicates that from threshold percolation there is a perfect continuity between the PPy grains. The high conductivity values obtained both through-plane and in-plane for PLA-PPy electrospun membranes confirm its possible application both in systems where the electrodes are located perpendicular to the membrane and in applications where the electrodes are in the plane of the membrane. This, in combination with its high specific surface area, high porosity and thermal stability for temperatures below $140^{\circ} \mathrm{C}$ allows its application with the throughplane disposition as solid, low cost, durable and tunable polymer electrolytes in applications such as PEMFCs, batteries, supercapacitors, sensors and photosensors. Likewise, the high surface conductivity of the membranes for the in-plane disposition, together with the biocompatibility of both PLA and PPy, extend the applications of these electrically conductive membranes to other fields such as tissue engineering and biomedical implantable devices.

\section{Authorship contribution statement}


Fernando Gisbert Roca: Methodology, Formal analysis, Investigation, Writing - original draft, Visualization. Abel García Bernabé: Investigation, Writing - Review \& Editing, Visualization. Vicente Compañ Moreno: Methodology, Writing - Review \& Editing, Funding acquisition. Cristina Martínez-Ramos: Conceptualization, Methodology, Writing - Review \& Editing, Supervision, Funding acquisition. Manuel Monleón Pradas: Conceptualization, Methodology, Writing - Review \& Editing, Supervision, Funding acquisition.

\section{Conflicts of interest}

There are no conflicts to declare.

\section{Acknowledgements}

The authors acknowledge financing from the Spanish Government's State Research Agency (AEI) through projects DPI2015-72863-EXP and RTI2018-095872-B-C22/ERDF. FGR acknowledges the scholarship FPU16/01833 of the Spanish Ministry of Universities. We thank the Electron Microscopy Service at the UPV, where the FESEM images were obtained.

\section{References}

1. R. McNeill, R. Siudak, J. H. Wardlaw, D. E. Weiss, Aust. J. Chem. 1963, 16, 1056.

2. B. A. Bolto, D. E. Weiss, Aust. J. Chem. 1963, 16, 1076.

3. B. A. Bolto, R. McNeill, D. E. Weiss, Aust. J. Chem. 1963, 16, 1090.

4. R. McNeill, D. E. Weiss, D. Willis, Aust. J. Chem. 1965, 18, 477.

5. B. A. Bolto, D. E. Weiss, D. Willis, Aust. J. Chem. 1965, 18, 487.

6. H. Shirakawa, E. J. Louis, A. G. MacDiarmid, C. K. Chiang, A. J. Heeger, J. Chem. Soc. Chem. Commun. 1977, 578, doi:10.1039/C39770000578.

7. N. Hall, Chem. Commun. 2003, 1, doi:10.1039/b210718j.

8. H. Hammache, L. Makhloufi, B. Saidani, Corros. Sci. 2003, 45, 2031. 
9. M. Mattioli-Belmonte et al., Mater. Sci. Eng. C 2005, 25, 43.

10. M. A. Careem, K. P. Vidanapathirana, S. Skaarup, K. West, Solid State Ionics 2004, 175, 725.

11. D. Ge et al., Electrochim. Acta 2009, 55, 271.

12. R. K. Sharma, A. C. Rastogi, S. B. Desu, Electrochem. commun. 2008, 10, 268.

13. J. Rubio Retama, E. López Cabarcos, D. Mecerreyes, B. López-Ruiz, Biosens. Bioelectron. 2004, 20, 1111.

14. $\quad$ L. X. Wang, X. G. Li, Y. L. Yang, React. Funct. Polym. 2001, 47, 125.

15. G. Sabouraud, S. Sadki, N. Brodie, Chem. Soc. Rev. 2000, 29, 283.

16. C. Li, H. Bai, G. Shi, Chem. Soc. Rev. 2009, 38, 2397.

17. T. H. Le, Y. Kim, H. Yoon, Polymers (Basel). 2017, 9.

18. S. I. Brahim, D. Maharajh, D. Narinesingh, A. Guiseppi-Elie, Anal. Lett. 2002, 35, 797.

19. K. J. Dunst, K. Cysewska, P. Kalinowski, P. Jasiński, IOP Conf. Ser. Mater. Sci. Eng. 2016, 104 .

20. H. K. Jun et al., Sensors Actuators, B Chem. 2003, 96, 576.

21. Y. Zhong, S. Lundemo, E. W. H. Jager, Smart Mater. Struct. 2018, 27.

22. A. Kisiel et al., Electrochem. commun. 2010, 12, 1568.

23. S. M. M. Morsi, M. E. A. El-Aziz, R. M. M. Morsi, A. I. Hussain, J. Coatings Technol. Res. 2018, doi:10.1007/s11998-018-00152-8.

24. H. Yamamoto, M. Fukuda, I. Isa, K. Yoshino, Electron. Commun. Japan (Part II Electron. 1993, 76, 88.

25. H. Yamamoto, M. Oshima, M. Fukuda, I. Isa, K. Yoshino, J. Power Sources 1996, 60, 173.

26. I. Sultana et al., Electrochim. Acta 2012, 83, 209.

27. J. Xia, L. Chen, S. Yanagida, J. Mater. Chem. 2011, 21, 4644. 
28. F. M. A. Almuntaser, S. Majumder, P. K. Baviskar, J. V. Sali, B. R. Sankapal, Appl. Phys. A Mater. Sci. Process. 2017, 123, 1.

29. D. Hao, B. Xu, Z. Cai, J. Mater. Sci. Mater. Electron. 2018, 29, 9218.

30. R. M. A. P. Lima, J. J. Alcaraz-Espinoza, F. A. G. Da Silva, H. P. De Oliveira, ACS Appl. Mater. Interfaces 2018, 10, 13783.

31. J. Avloni et al., Screening 2006, 6, doi:10.1177/0892705707076718.

32. C. Y. Lee et al., Polym. Adv. Technol. 2002, 13, 577.

33. E. Håkansson, A. Amiet, S. Nahavandi, A. Kaynak, Eur. Polym. J. 2007, 43, 205.

34. A. H. El-Shazly, A. A. Wazzan, Int. J. Electrochem. Sci. 2012, 7, 1946.

35. T. G. DRAGICA CHAMOVSKA, ALEKSANDRA PORJAZOSKA KUJUNDZISKI, Zaštita Mater. 2013, 54, 229.

36. H. Zhao, L. Li, J. Yang, Y. Zhang, J. Power Sources 2008, 184, 375.

37. S. Y. Huang, P. Ganesan, B. N. Popov, Appl. Catal. B Environ. 2009, 93, 75.

38. H. S. Park, Y. J. Kim, Y. S. Choi, W. H. Hong, D. Jung, J. Power Sources 2008, 178, 610.

39. C. Feng et al., Biosens. Bioelectron. 2010, 25, 1516.

40. J. Y. Lee, C. A. Bashur, A. S. Goldstein, C. E. Schmidt, Biomaterials 2009, 30, 4325.

41. J. F. Zhou et al., Neural Regen. Res. 2016, 11, 1644.

42. S. Aznar-Cervantes et al., Bioelectrochemistry 2012, 85, 36.

43. P. M. George et al., Biomaterials 2005, 26, 3511.

44. J. Wang et al., Phys. Chem. Chem. Phys. 2017, 19, 21165.

45. T. Uyar, L. Toppare, J. Hacaloglu, J. Macromol. Sci. - Pure Appl. Chem. 2001, 38 A, 1141.

46. B. Zinger, P. Shaier, A. Zemel, Synth. Met. 1991, 40, 283.

47. N. N. Ha, N. T. Cuong, H. Van Hung, H. M. Hung, V. Q. Trung, J. Mol. Model. 2017, 
48. R. C. D. Peres, V. F. Juliano, M. A. De Paoli, S. Panero, B. Scrosati, Electrochim. Acta 1993, 38,869 .

49. M. A. De Paoli, R. C. D. Peres, S. Panero, B. Scrosati, Electrochim. Acta 1992, 37, 1173.

50. H. K. Lim, S. O. Lee, K. J. Song, S. G. Kim, K. H. Kim, J. Appl. Polym. Sci. 2005, 97, 1170.

51. U. Carragher, C. B. Breslin, Electrochim. Acta 2018, 291, 362.

52. C. Arribas, D. Rueda, Synth. Met. 1996, 79, 23.

53. T. M. Wu, H. L. Chang, Y. W. Lin, Polym. Int. 2009, 58, 1065.

54. C. Jin, F. Yang, W. Yang, J. Appl. Polym. Sci. 2006, 101, 2518.

55. A. Kaynak, Fibers Polym. 2009, 10, 590.

56. L. A. Samuelson, M. A. Druy, Macromolecules 1986, 19, 824.

57. H. Hou, Q. Liao, J. Duan, S. Liu, Y. Yao, Surf. Innov. 2018, 6, 56.

58. I. Sultana et al., Electrochim. Acta 2012, 60, 201.

59. C. Jérôme, L. Martinot, D. Strivay, G. Weber, R. Jérôme, Synth. Met. 2001, 118, 45.

60. H. Zhao, W. E. Price, C. O. Too, G. G. Wallace, D. Zhou, J. Memb. Sci. 1996, 119, 199.

61. R. Ansari Khalkhali, W. E. Price, G. G. Wallace, React. Funct. Polym. 2003, 56, 141.

62. M. Pyo, J. R. Reynolds, L. F. Warren, H. O. Marcy, Synth. Met. 1994, 68, 71.

63. P. Murray, G. M. Spinks, G. G. Wallace, R. P. Burford, Synth. Met. 1997, 84, 847.

64. J. Chengyou, Y. Fenglin, Sensors Actuators, B Chem. 2006, 114, 737.

65. S. Li, Y. Qiu, X. Guo, J. Appl. Polym. Sci. 2009, 114, 2307.

66. T. Raudsepp, M. Marandi, T. Tamm, V. Sammelselg, J. Tamm, Electrochim. Acta 2014, $122,79$.

67. V. Syritski, A. Öpik, O. Forsén, Electrochim. Acta 2003, 48, 1409.

68. Y. Fang et al., J. Power Sources 2010, 195, 674. 
69. T. Qian et al., Biosens. Bioelectron. 2014, 58, 237.

70. J. Zhang, X. S. Zhao, J. Phys. Chem. C 2012, 116, 5420.

71. W. Li et al., Nano Lett. 2013, 13, 5534.

72. C. Zhu, J. Zhai, D. Wen, S. Dong, J. Mater. Chem. 2012, 22, 6300.

73. A. Esfandiari, World Appl. Sci. J. 2008, 3, 470.

74. C. Ding, X. Qian, G. Yu, X. An, Cellulose 2010, 17, 1067.

75. L. Yuan et al., Energy Environ. Sci. 2013, 6, 470.

76. Y. Lu, P. Tao, N. Zhang, S. Nie, Carbohydr. Polym. 2020, 245, 116463.

77. Y. Zhang, N. Hao, X. Lin, S. Nie, Carbohydr. Polym. 2020, 234, 115888.

78. Y. Wang, G. A. Sotzing, R. A. Weiss, Chem. Mater. 2008, 20, 2574.

79. D. E. Henton, P. Gruber, J. Lunt, J. Randall, Nat. Fibers, Biopolym. Biocomposites 2005, $48674,527$.

80. J. Lunt, Polym. Degrad. Stab. 1998, 3910, 145.

81. P. Mróz, S. Białas, M. Mucha, H. Kaczmarek, Thermochim. Acta 2013, 573, 186.

82. M. C. Araque-Monrós et al., Polym. Degrad. Stab. 2013, 98, 1563.

83. Y. Ramot, M. Haim-Zada, A. J. Domb, A. Nyska, Adv. Drug Deliv. Rev. 2016, 107, 153.

84. D. da Silva et al., Chem. Eng. J. 2018, 340, 9.

85. J. Schindelin et al., Nat. Methods 2012, 9, 676.

86. D. Garlotta, J. Polym. Environ. 2001, 9, 63.

87. J. P. Mofokeng, A. S. Luyt, T. Tábi, J. Kovács, J. Thermoplast. Compos. Mater. 2012, $25,927$.

88. B. W. Chieng, N. A. Ibrahim, W. M. Z. W. Yunus, M. Z. Hussein, Polymers (Basel). 2014, 6, 93.

89. H. K. Chitte, G. N. Shinde, N. V. Bhat, V. E. Walunj, J. Sens. Technol. 2011, 01, 47.

90. T. Uyar, L. Toppare, J. Hacaloğlu, J. Anal. Appl. Pyrolysis 2002, 64, 1. 
91. H. J. Schütt, E. Gerdes, J. Non. Cryst. Solids 1992, 144, 1.

92. H. J. Schütt, E. Gerdes, J. Non. Cryst. Solids 1992, 144, 14.

93. T. S. Sørensen, V. Compañ, R. Diaz-Calleja, J. Chem. Soc. - Faraday Trans. 1996, 92, 1947.

94. J. R. Sangoro et al., Phys. Rev. E - Stat. Nonlinear, Soft Matter Phys. 2008, 77.

95. A. Serghei, M. Tress, J. R. Sangoro, F. Kremer, Phys. Rev. B - Condens. Matter Mater. Phys. 2009, 80, 184301.

96. D. Fragiadakis, S. Dou, R. H. Colby, J. Runt, J. Chem. Phys. 2009, 130, 064907.

97. I. S. Chronakis, S. Grapenson, A. Jakob, Polymer (Guildf). 2006, 47, 1597.

98. Y. Zou et al., ACS Appl. Mater. Interfaces 2016, 8, 12576.

99. T. Bashir et al., Polym. Sci. - Ser. A 2017, 59, 902.

100. A. A. Khan, R. Hussain, S. Shaheen, New J. Chem. 2016, 40, 2200. 


\section{A}

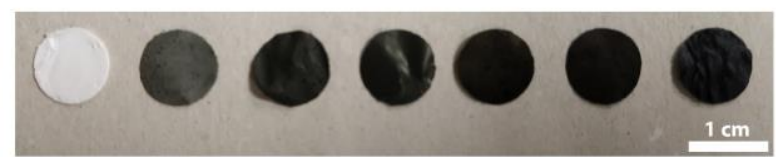

B

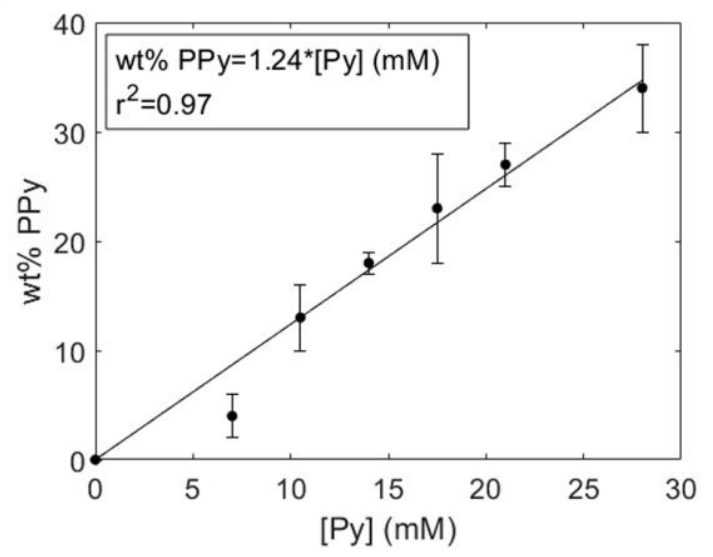

Figure 1. A: From left to right, macroscopic images of PLA (EPLA) and PLA-PPy (E4, E13, E18, E23, E27 and E34) electrospun membranes. B: PPy mass fraction of electrospun membranes for the different Py concentrations used in the coating process. A linear relationship between both parameters can be observed. 

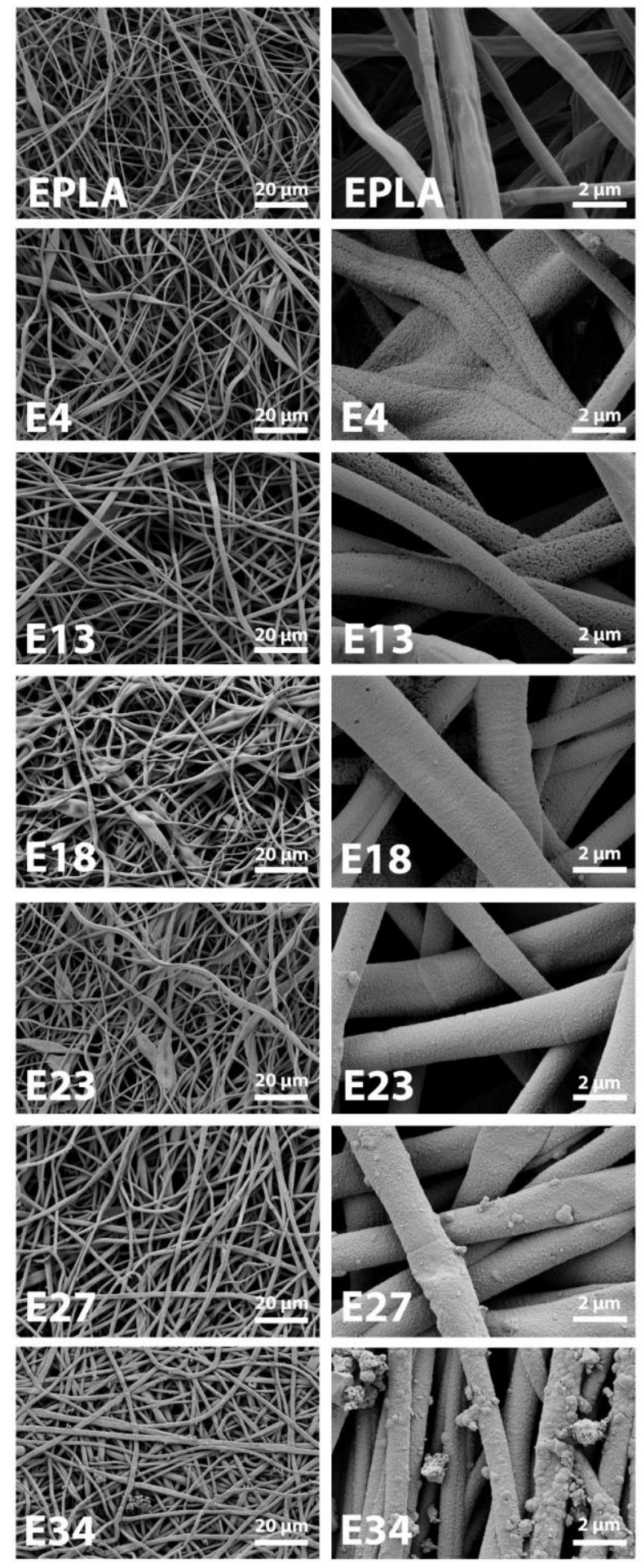

Figure 2. FESEM images of PLA (EPLA) and PLA-PPy (E4, E13, E18, E23, E27 and E34) electrospun membranes with a random orientation of the nanofibers. EPLA: Smooth surface. E4 and E13: Inhomogeneous coating with discontinuities. E18: More homogeneous coating, but still with some discontinuities. E23 and E27: Homogeneous coating without aggregates. E34: Homogeneous coating, but with PPy aggregates. 


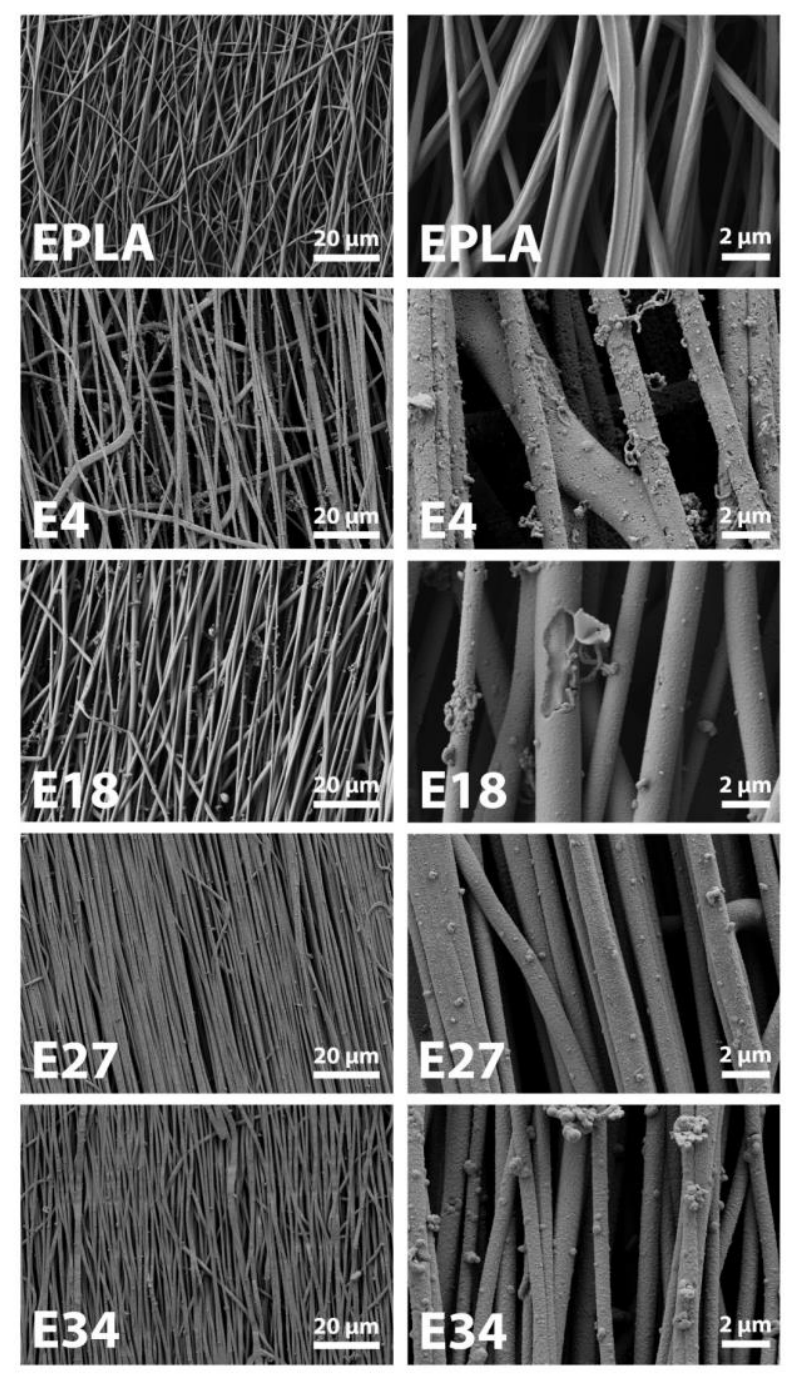

Figure 3. FESEM images of PLA (EPLA) and PLA-PPy (E4, E18, E27 and E34) electrospun membranes with an aligned orientation of the nanofibers. EPLA: Smooth surface. E4: Inhomogeneous coating with discontinuities. E18: More homogeneous coating, but still with some discontinuities. E27: Homogeneous coating. E34: Homogeneous coating, but with PPy aggregates. 
A
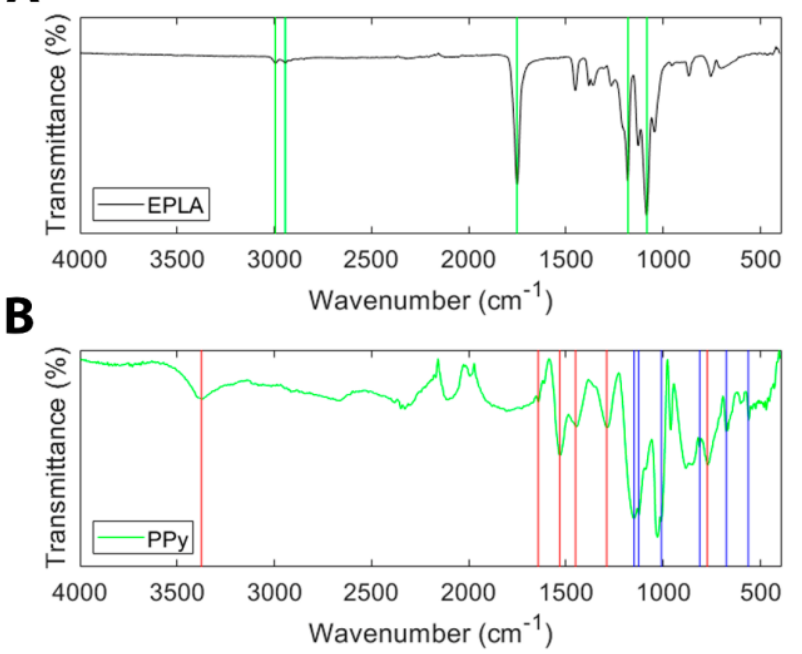

Figure 4. FTIR spectra of electrospun-PLA membrane (EPLA), as well as pure PPy doped with pTS (PPy). Green, red and blue vertical lines indicate the characteristic peaks of PLA, PPy and pTS, respectively.

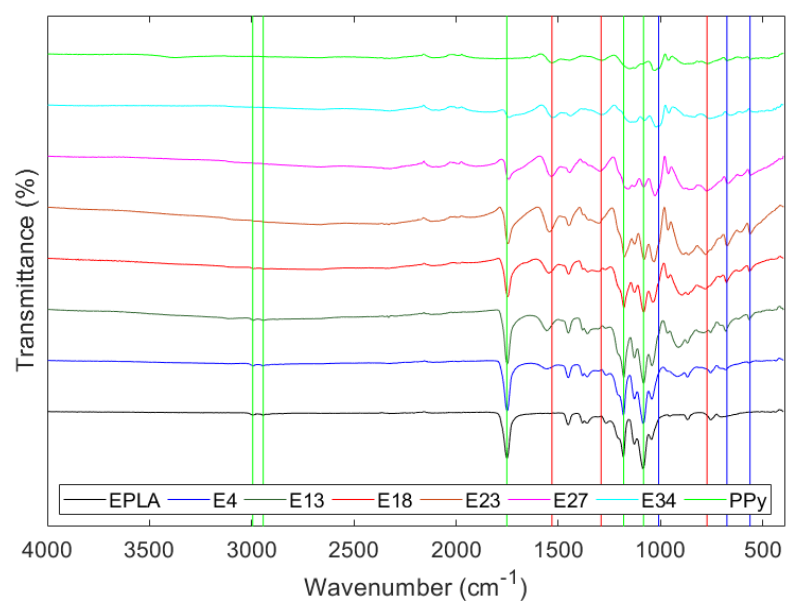

Figure 5. FTIR spectra of PLA (EPLA) and PLA-PPy (E4, E13, E18, E23, E27 and E34) electrospun membranes, as well as pure PPy. Green, red and blue vertical lines indicate the characteristic peaks of PLA, PPy and pTS, respectively. 


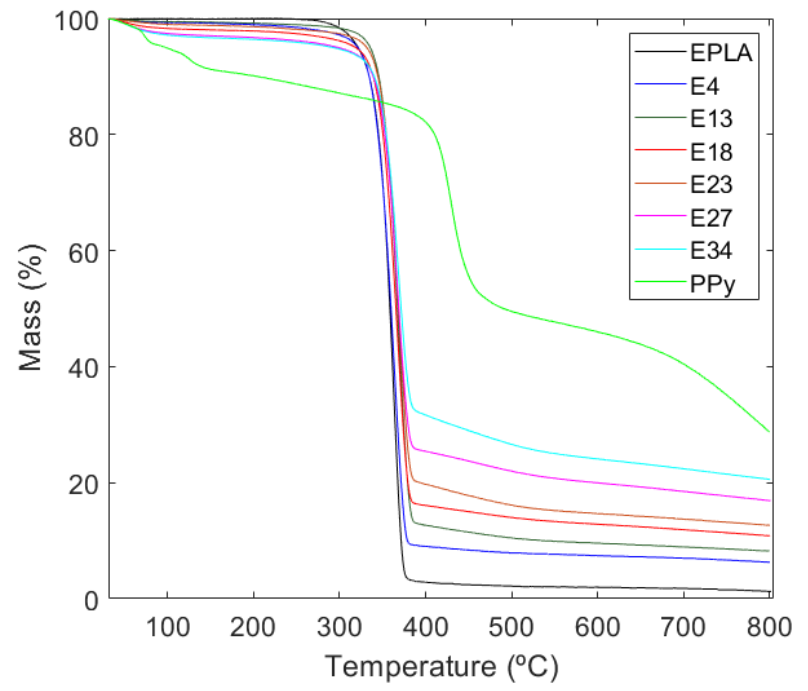

Figure 6. TGA of PLA (EPLA) and PLA-PPy (E4, E13, E18, E23, E27 and E34) electrospun membranes, as well as pure PPy.
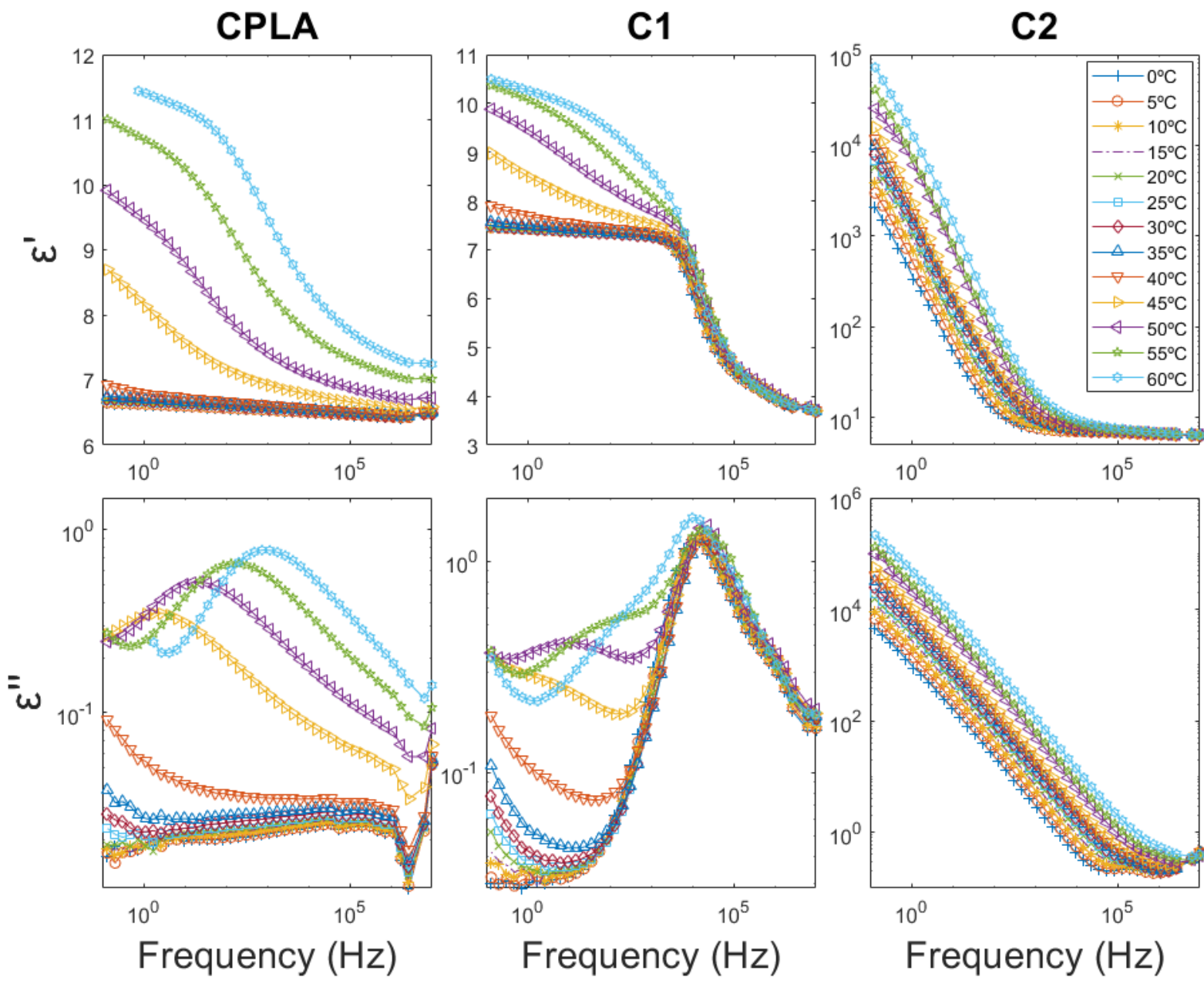

Frequency $(\mathrm{Hz})$

Figure 7. Real and imaginary part of the complex permittivity, $\varepsilon^{\prime}$ and $\varepsilon^{\prime}$ ', respectively, for PLA (CPLA) and PLA-PPy $(\mathrm{C} 1$ and $\mathrm{C} 2)$ cast films at different temperatures in the interval from $0^{\circ} \mathrm{C}$ to $60^{\circ} \mathrm{C}$. 


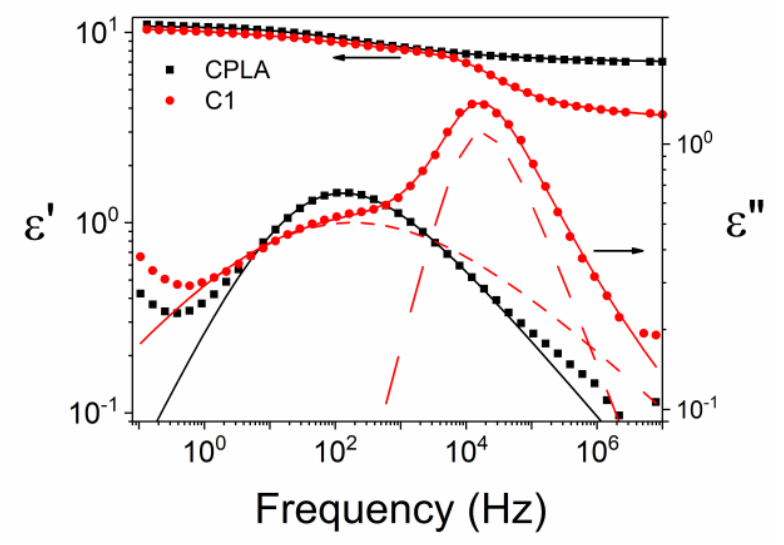

Figure 8. Deconvolutions of the real and imaginary part of the complex permittivity at $55^{\circ} \mathrm{C}$ for PLA (CPLA) and PLA-PPy (C1) cast films, respectively.

A

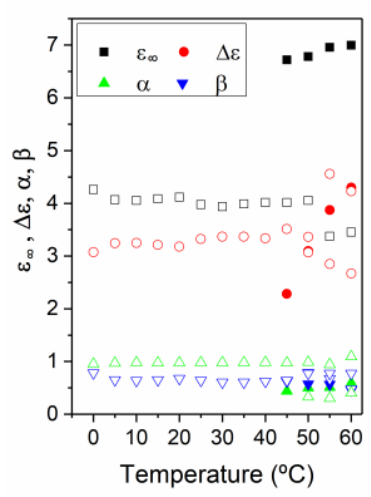

B

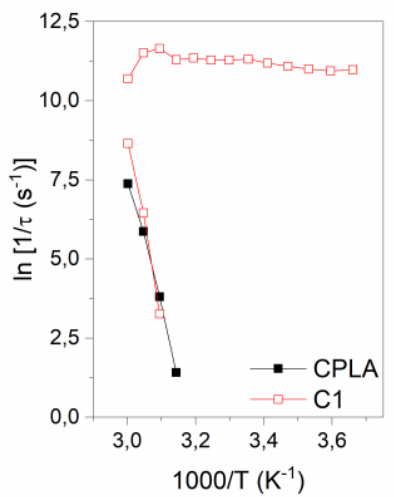

Figure 9. A: Values of the parameters $\Delta \varepsilon, \varepsilon_{\infty}, \alpha$ and $\beta$ for the temperatures where the relaxation is present for the PLA (CPLA) (solid) and PLA-PPy (C1) (open) cast films. B: Variation of the relaxation time with temperature for the PLA (CPLA) and PLA-PPy (C1) cast films. 


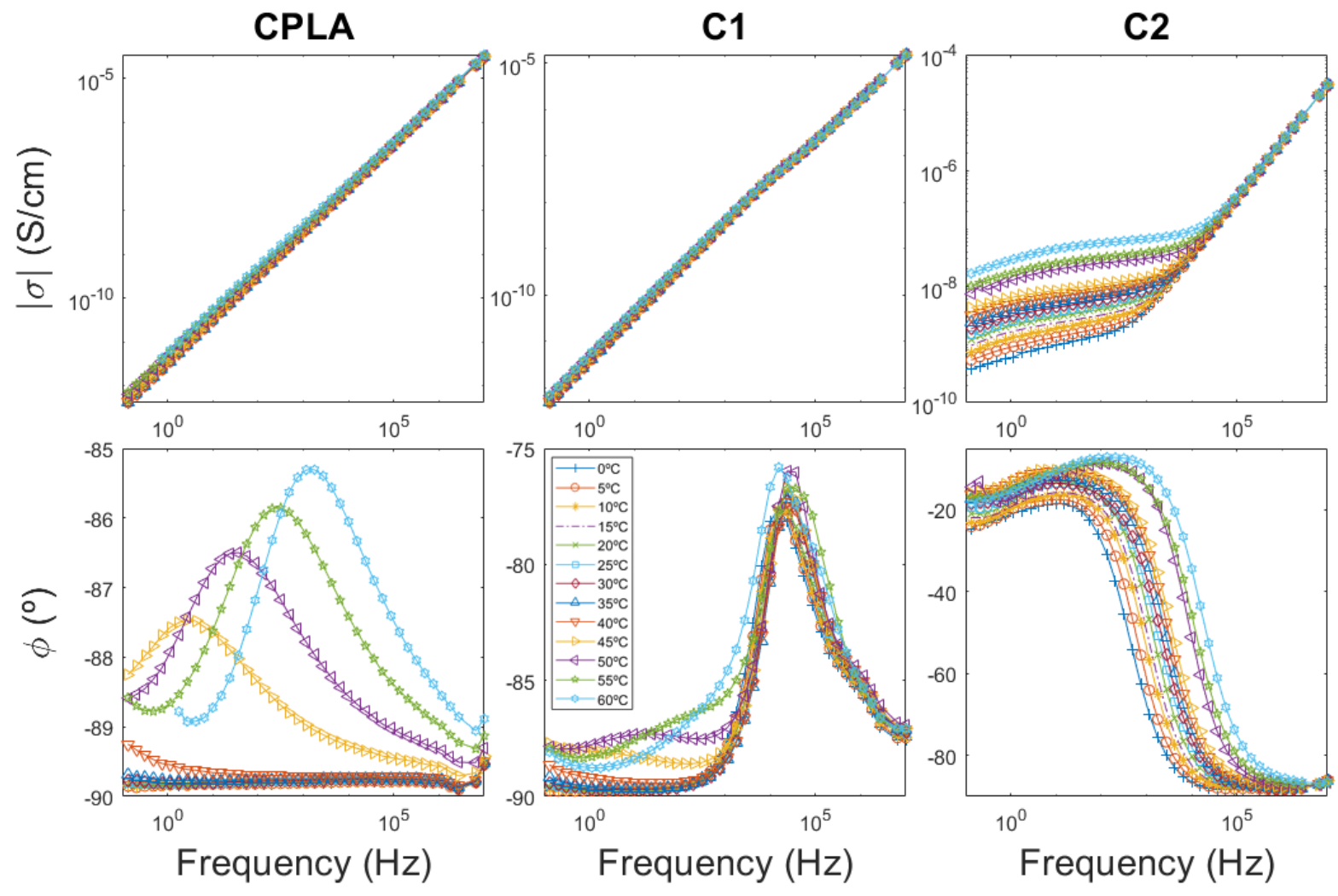

Figure 10. Bode diagram for the PLA (CPLA) and PLA-PPy (C1 and C2) cast films.
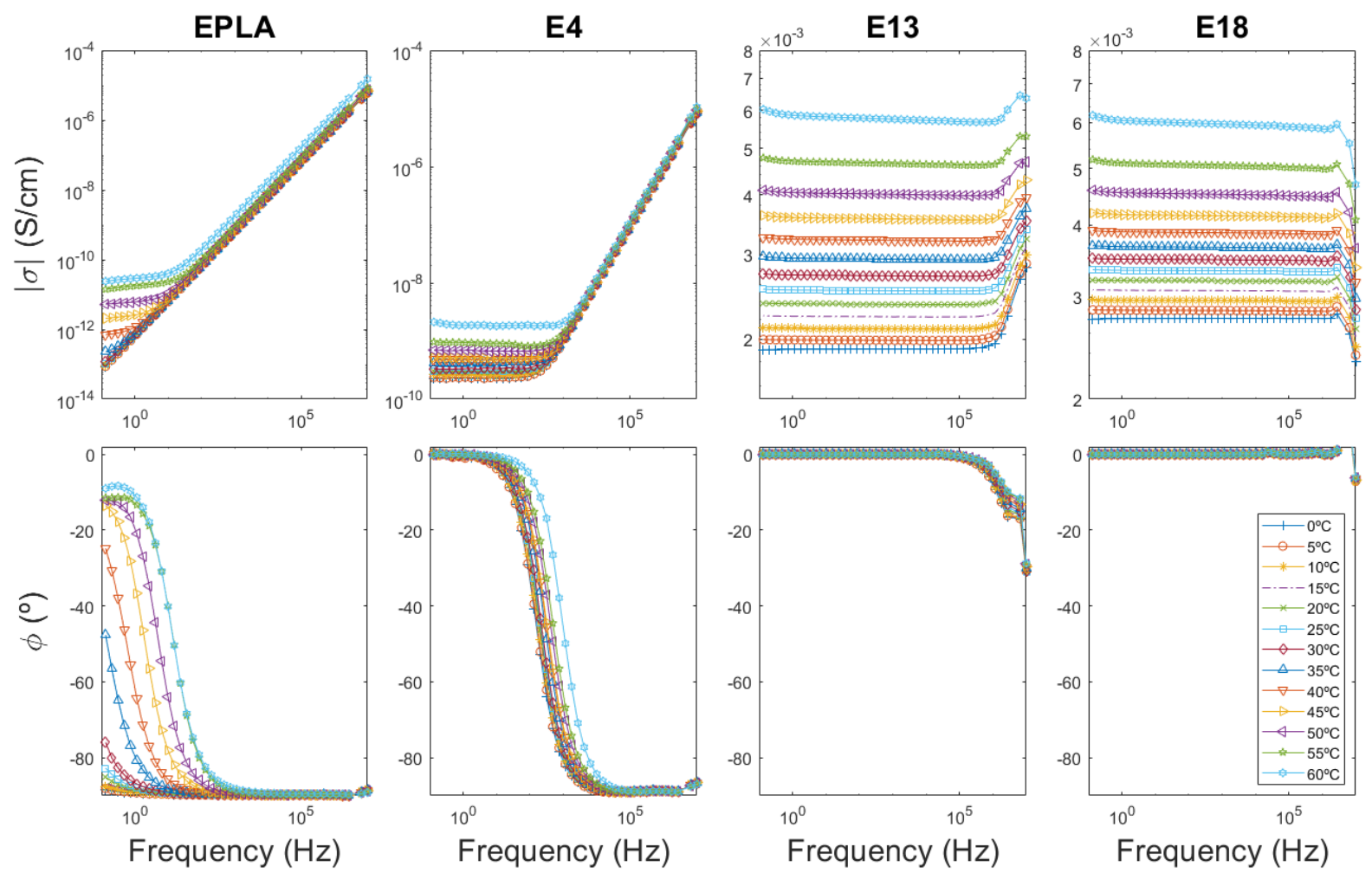

Figure 11. Bode diagram for PLA (EPLA) and PLA-PPy (E4, E13 and E18) electrospun membranes 
A

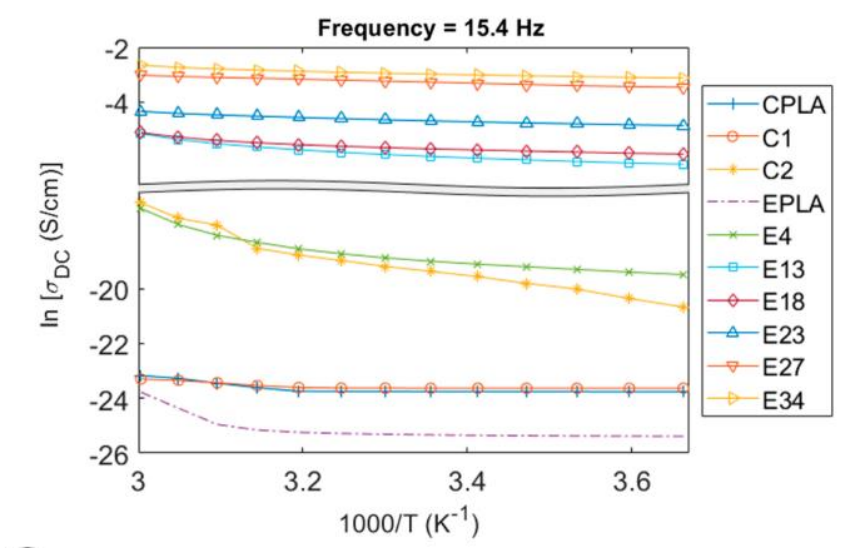

C

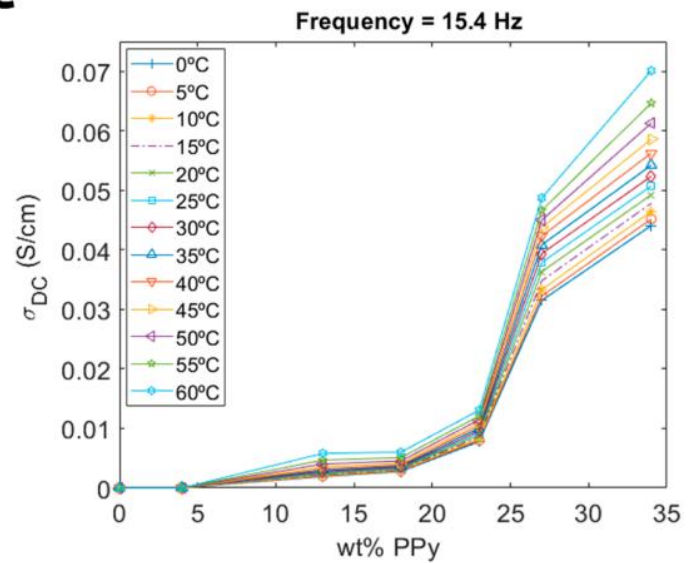

B

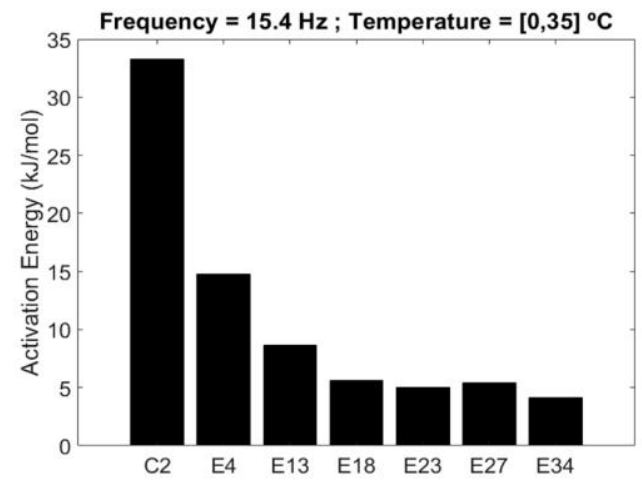

D

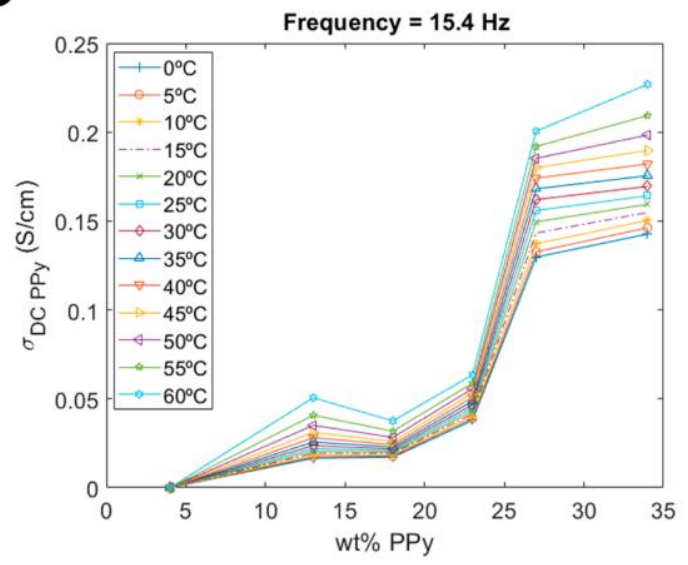

Figure 12. Through-plane electrical characterization of PLA-PPy composites. A: Arrhenius plot for the DC conductivity obtained from the Bode diagrams for CPLA, C1, C2, EPLA, E4, $\mathrm{E} 13, \mathrm{E} 18, \mathrm{E} 23, \mathrm{E} 27$ and E34 (frequency $=15.4 \mathrm{~Hz}$ ). B: Activation energy for C2, E4, E13, E18, $\mathrm{E} 23, \mathrm{E} 27$ and E34 (frequency $=15.4 \mathrm{~Hz}$, temperature $=\left[0,35{ }^{\circ} \mathrm{C}\right.$ ). $\mathrm{C}$ : Electrical conductivity vs. mass fraction of PPy for PLA-PPy electrospun membranes. D: PPy electrical conductivity vs. mass fraction of PPy for electrospun membranes.

\section{A}

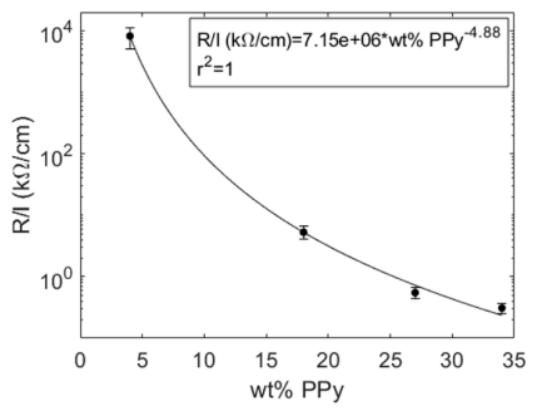

B

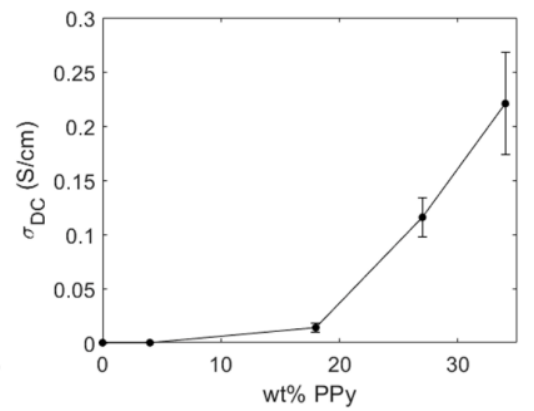

C

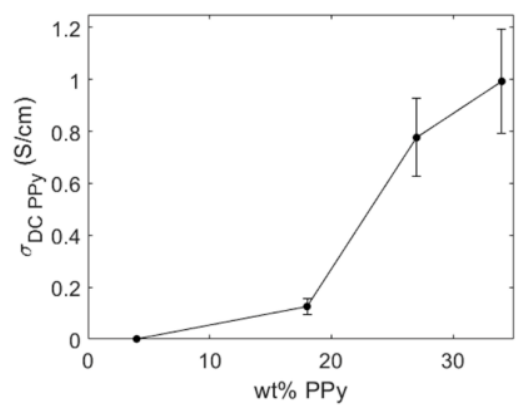

Figure 13. In-plane electrical characterization of PLA-PPy electrospun membranes (E4, E18, E27 and E34) at room temperature. A: Surface resistance normalized by the distance between contacts. B: Electrical conductivity vs. mass fraction of PPy. C: PPy conductivity vs. mass fraction of PPy. 
A

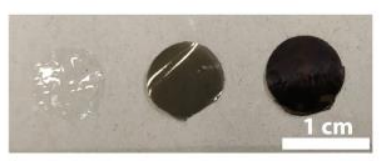

B

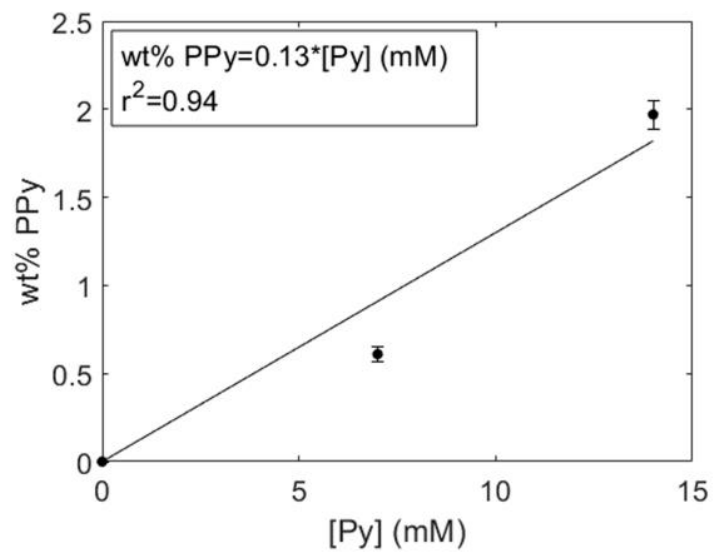

Figure S1. A: From left to right, macroscopic images of PLA (CPLA) and PLA-PPy (C1 and C2) casting films. B: PPy mass fraction of casting films for the different Py concentrations used in the coating process. A linear relationship between both parameters can be observed.

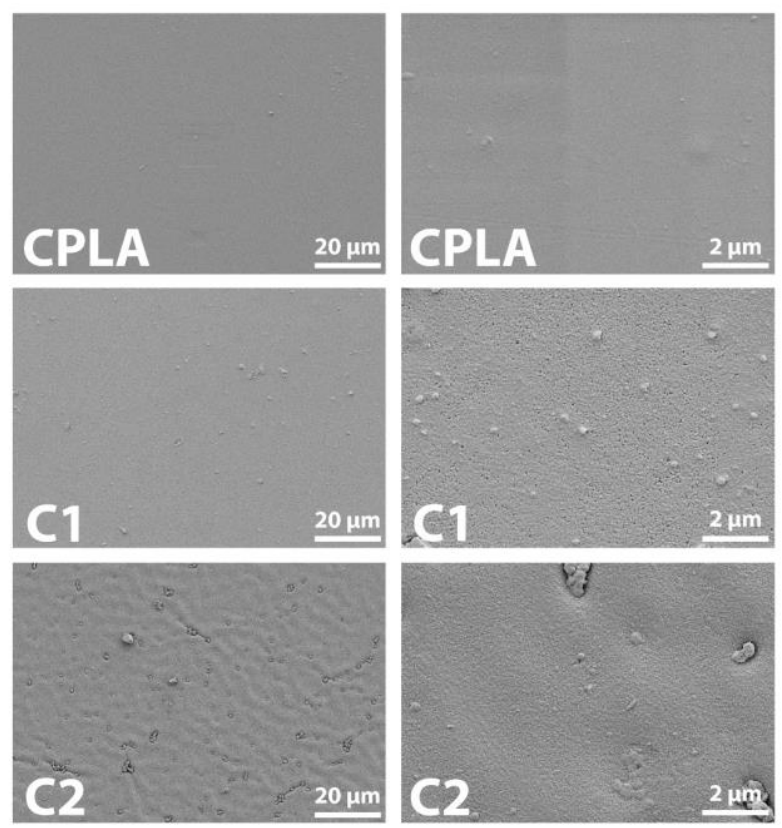

Figure S2. FESEM images of PLA (CPLA) and PLA-PPy (C1 and C2) casting films. A flat and smooth surface without porosity can be observed for CPLA, while a rougher surface is observed when the PPy is present (C1 and C2). 


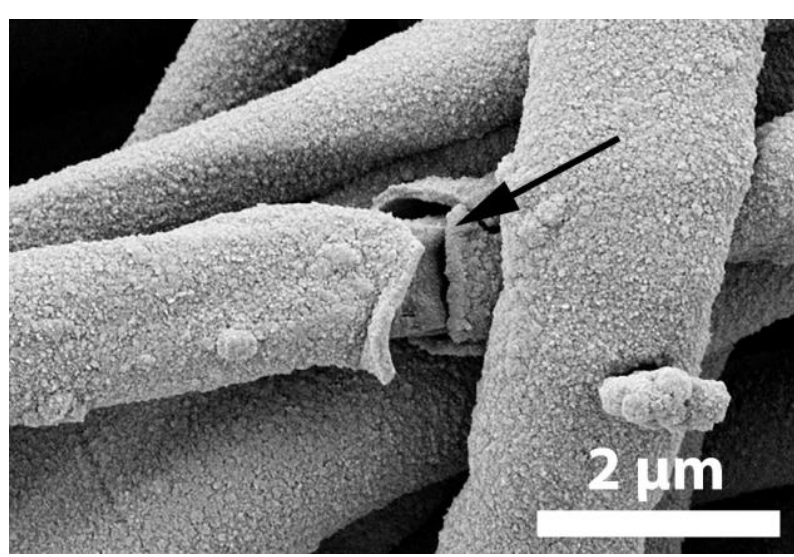

Figure S3. Detail of E23 showing a cross-section of the PPy coating, with a thickness of the coating of around $100 \mathrm{~nm}$.

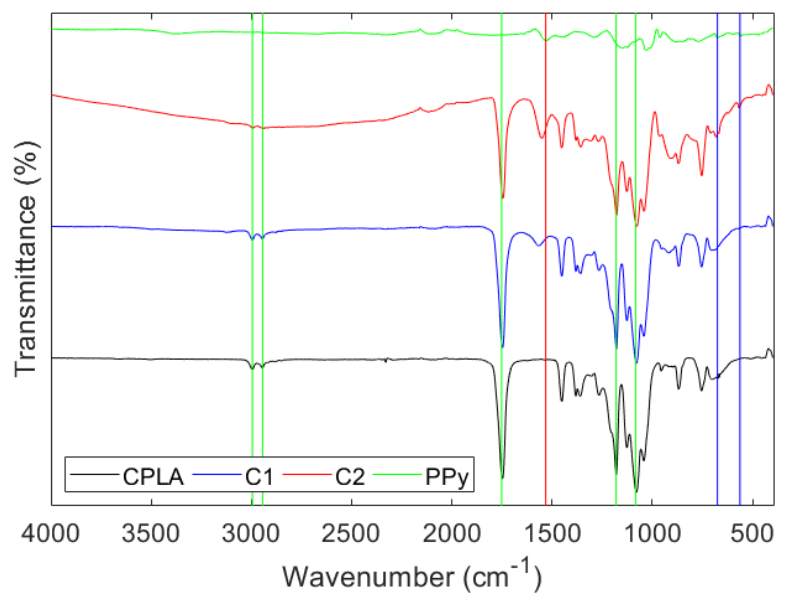

Figure S4. FTIR spectra of PLA (CPLA) and PLA-PPy (C1 and C2) casting films, as well as pure PPy. Green, red and blue vertical lines indicate the characteristic peaks of PLA, PPy and pTS, respectively. 

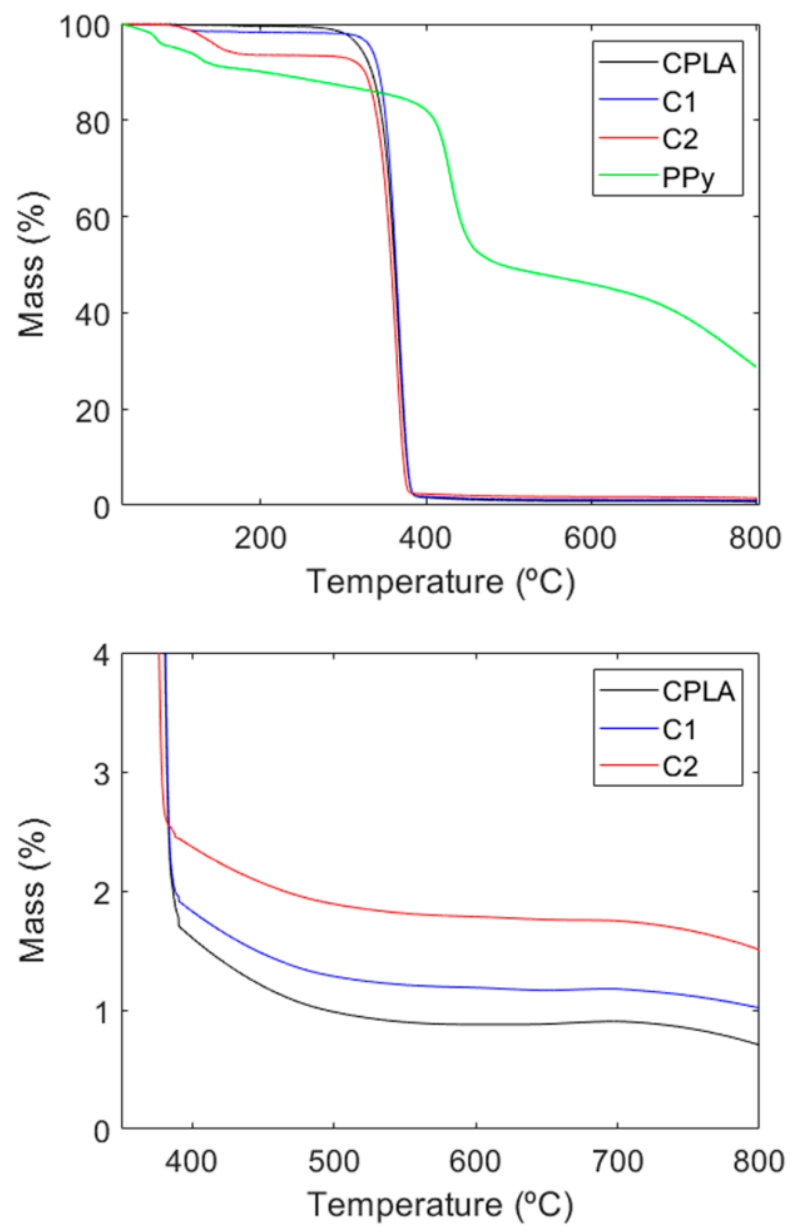

Figure S5. TGA of PLA (CPLA) and PLA-PPy (C1 and C2) casting films, as well as pure PPy. Up: Complete graph. Down: Detail of the graph.

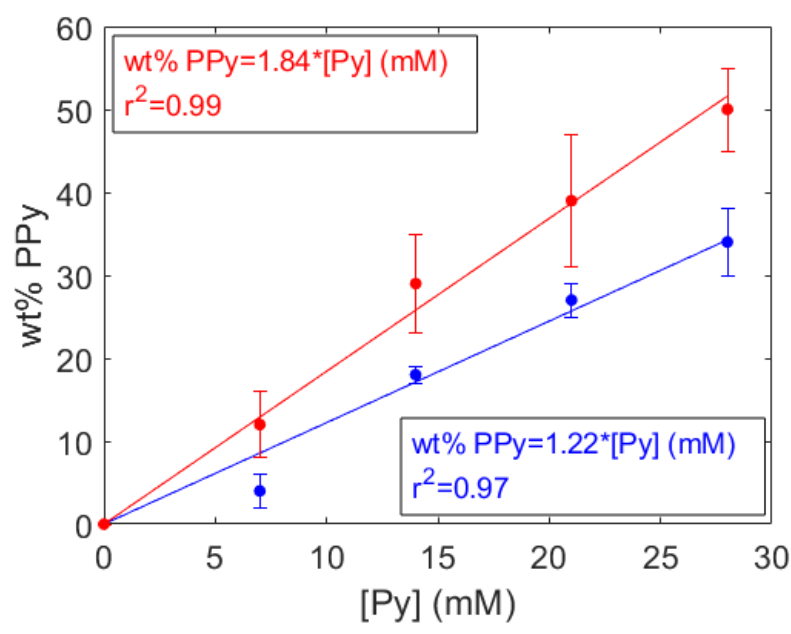

Figure S6. Mass fraction of PPy in function of the Py concentration used for the coating obtained by two different methods: weighing the electrospinning membranes before and after the PPy coating (in blue) and using the TGA residues (in red). There is an oversizing of 50\% of the mass fraction of PPy when using TGA residues that could be produced by a greater retention of PLA volatiles by the PPy coating. 


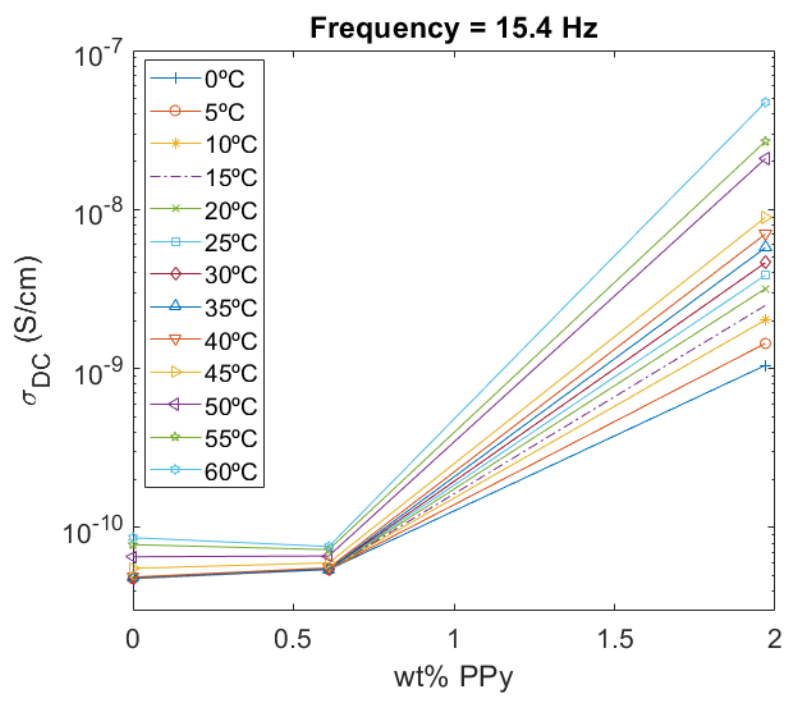

Figure S7. Electrical conductivity vs. mass fraction of PPy for PLA (CPLA) and PLA-PPy (C1 and $\mathrm{C} 2$ ) casting films.

E23
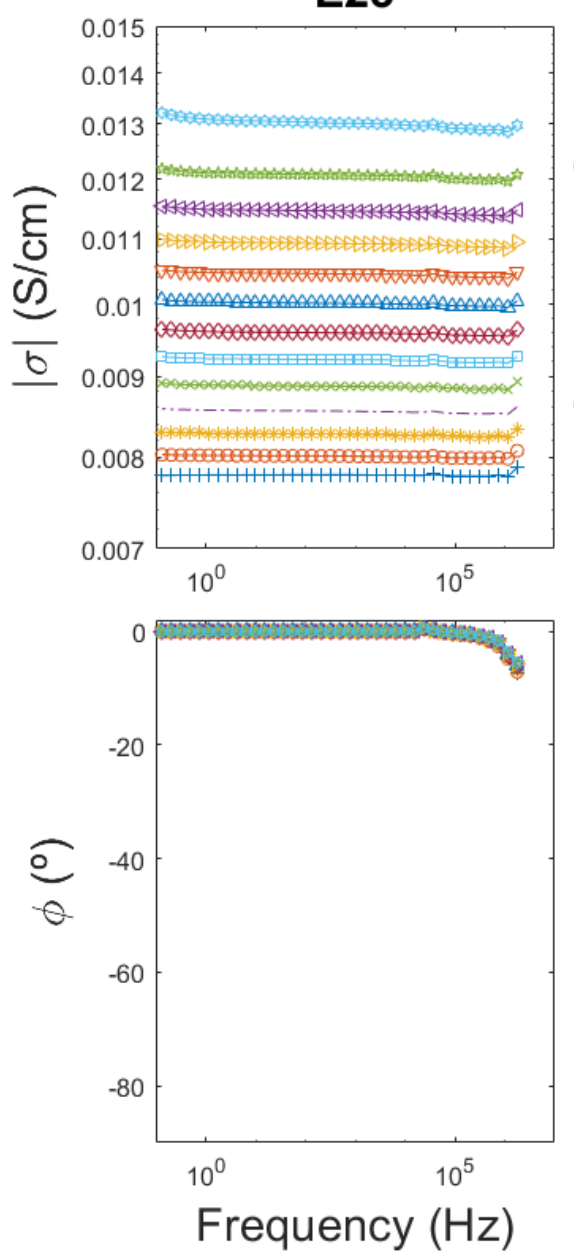

E27
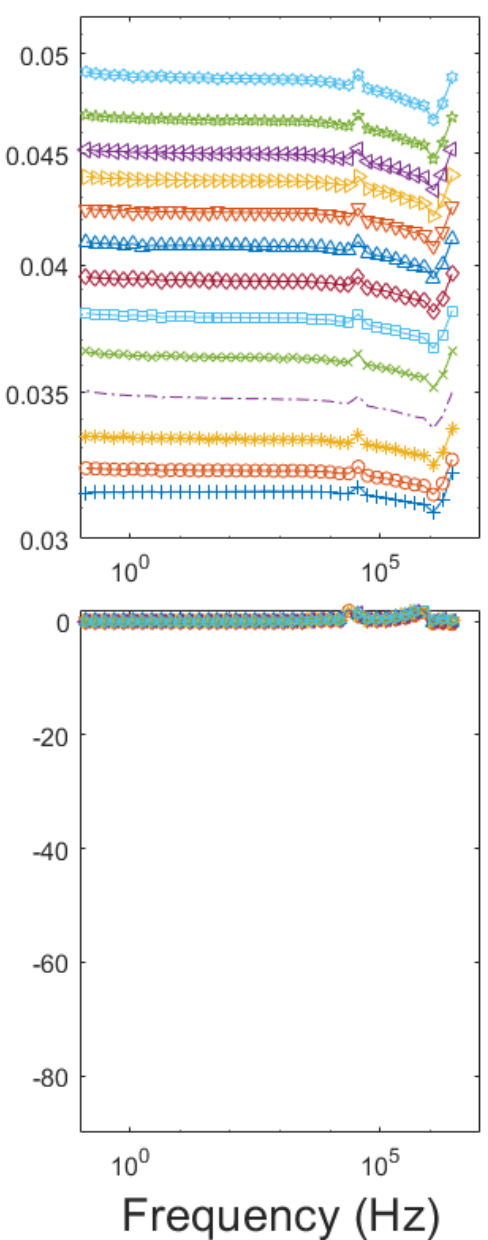

E34
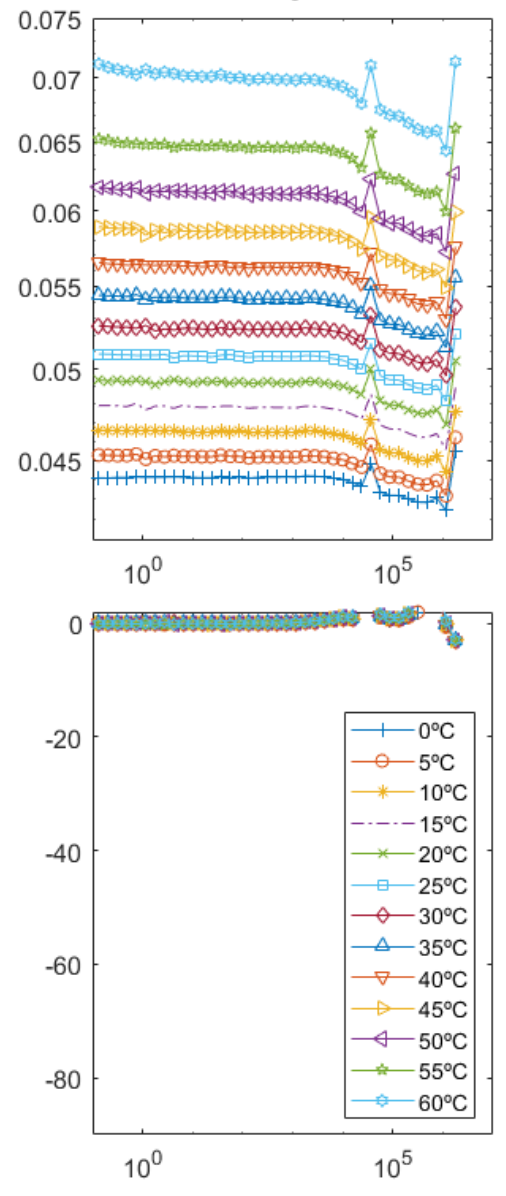

Frequency $(\mathrm{Hz})$

Figure S8. Bode diagram for PLA-PPy (E23, E27 and E34) electrospinning membranes. 